\title{
Factor Adjustments after Deregulation: Panel Evidence from Colombian Plants
}

Marcela Eslava, John Haltiwanger, Adriana Kugler and Maurice Kugler

CID Working Paper No. 184

September 2008

(C) Copyright 2008 Marcela Eslava, John Haltiwanger, Adriana

Kugler, Maurice Kugler and the President and Fellows of Harvard College

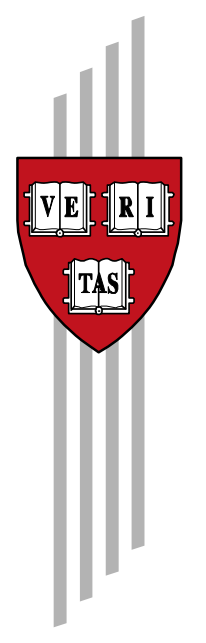

\section{Working Papers Center for International Development at Harvard University}




\title{
Factor Adjustments after Deregulation: Panel Evidence from Colombian Plants*
}

\author{
Marcela Eslava, John Haltiwanger, Adriana Kugler and Maurice Kugler ${ }^{\dagger}$
}

September 2008

\begin{abstract}
We analyze employment and capital adjustments using plant data from the Colombian Annual Manufacturing Survey. We estimate adjustment functions for capital and labor as a non-linear function of the gaps between desired and actual factor levels, allowing for interdependence in adjustments of the two factors. In addition to non-linear employment and capital adjustments in response to market fundamentals, we find that capital shortages reduce hiring and labor surpluses reduce capital shedding. We also find that after factor market deregulation in Colombia in 1991, factor adjustment hazards increased on the job destruction and capital formation margins. Finally, we find that completely eliminating frictions in factor adjustment would yield a substantial increase in aggregate productivity through improved allocative efficiency. Yet, the actual impact of the Colombian deregulation on aggregate productivity through factor adjustment was modest.
\end{abstract}

Keywords: Reallocation, joint factor adjustment, irreversibility, deregulation.

JEL Codes: E22, E24, O11, C14, J63.

\footnotetext{
*We thank Andres Fernández, Pablo Medina, Diana Hincapié, and Rafael Santos for excellent research assistance, and DANE for data access. We thank seminar participants from CEP/LSE, Columbia, Exeter, Fedesarrollo, IFS/UCL, Los Andes, Michigan, MIT, NBER, and Yale, and especially two anonymous referees and Esther Duflo, Josh Angrist, Orazio Attanasio, Eli Berman, Ernst Berndt, Nick Bloom, Ricardo Caballero, Ken Chay, Eduardo Engel, Penny Goldberg, Rachel Griffith, Dan Hamermesh, Charles Hulten, Norman Loayza, Steve Pischke, Luis Serven, Jagadeesh Sivadasan, Chad Syverson and John Van Reenen for very useful comments. Research support was provided by the World Bank, the Tinker Foundation, a GEAR grant from the University of Houston, and NSF Grant SES-0617816.

${ }^{\dagger}$ Marcela Eslava: Universidad de Los Andes. John Haltiwanger: University of Maryland, NBER and IZA. Adriana Kugler: University of Houston, NBER, CEPR, and IZA. Maurice Kugler: Wilfrid Laurier University, CIGI and Center for International Development at Harvard University.
} 


\section{Introduction}

Well-functioning market economies require producers to change their input mix in response to shocks. However, there is limited scope for continual adjustment of the main factors of production, i.e., capital and labor. Instead, there is evidence that changes in investment and employment are associated with substantial adjustments rather than frequent tinkering (e.g., Caballero, Engel and Haltiwanger (1995, 1997), Cooper, Haltiwanger and Power (1999), Doms and Dunne (1998), Gelos and Isgut (2001), Nilsen and Schiantarelli (2003) and Gourio and Kashyap (2007)). One explanation of these findings is that when firms face fixed adjustment costs and irreversibilities, it is only optimal to make large adjustments. Factor adjustments have mainly been studied in the context of individual adjustment margins, and the few studies that analyze joint adjustments of capital and labor use sectoral level data, thus assuming convex adjustment costs at the establishment level (Nadiri and Rosen (1969), Shapiro (1986), Rossana (1990), and Hall (2004)). ${ }^{1}$

In this paper, we study the joint evolution of employment growth and investment using panel data for Colombian manufacturing plants. In contrast to most previous studies using micro data, our framework analyzes non-linear adjustment allowing for interactions between the capital and labor margins. If factor demands are indeed inter-related, this implies limited scope of piecemeal reforms. An interesting question in the context of developing and transition economies is whether market reforms in these countries have been effective in increasing factor adjustments. In this paper, we focus on how inter-related labor and capital adjustments changed after the introduction of market reforms in Colombia in the early 1990s.

Colombia is an interesting case because, in the early 1990s, this country undertook substantial market reforms, partly intended to liberalize labor and financial markets and to facilitate factor adjustments. Reforms introduced in 1990 and 1991 reduced dismissal costs; liberalized deposit rates; eliminated credit subsidies; modernized capital market and banking legislation; and removed restrictions on inflows of foreign direct investment. In addition, Colombia has unique longitudinal microeconomic data on businesses with information on both plant-level quantities and prices for both outputs and inputs, which permits to separately measure productivity, demand and cost shocks and to examine the impact of these shocks on factor adjustments. This is an improvement over most of the existing literature which measures productivity by deflating revenue by industry-level prices, likely

\footnotetext{
${ }^{1}$ Two exceptions, discussed in more detail below, are the studies by Polder, Pfann and Letterie (2004) and Bloom (2007).
} 
confounding productivity differences across plants with demand shifts or market power variation within industries. ${ }^{2}$

Our paper makes a number of methodological innovations. First, we analyze interrelated factor demands in the presence of non-linear adjustment functions, allowing us to identify dynamic complementarities across factors. Second, our rich micro data contains plant-level output and input prices, allowing us to estimate productivity and demand shocks, which are used along with input price shocks to estimate desired factor demands. Thus, a strength of our analysis is that we directly measure desired factor levels by estimating the expressions resulting from the frictionless maximization problem rather than having to rely on relationships between employment and hours and fixed capital and energy utilization, like other studies do.

We find strong evidence of non-linear micro adjustments, as businesses adjust by a greater amount when the gaps between desired and actual levels are larger. In addition, we find that frictions in capital and labor adjustments reinforce each other. Bigger capital shortages reduce hiring and bigger labor surpluses reduce the shedding of capital. We also find evidence that the reforms increased labor adjustment, especially on the job destruction side, as well as capital adjustment but only in response to relatively small shortages. By contrast, plants became less responsive to capital surpluses. A potential explanation for this is that the reforms may have induced a substitution away from capital destruction to job destruction. One way of thinking about the latter is that the reforms may have increased the relative importance of technology-related frictions relative to institutional frictions. In this respect, we note that the adjustment function of capital after the Colombian reforms closely mimics those estimated for the U.S., suggesting that the Colombian capital adjustments may now be driven much more by technological and less by institutional factors as in the U.S.

Finally, we take advantage of our ability to estimate physical productivity to examine how the removal of frictions to adjustment affects allocative efficiency. We find that if adjustment frictions could be completely eliminated there would be a substantial increase in productivity. On the other hand, our counterfactual analysis reveals positive but modest impacts of adjustment changes on aggregate productivity after the reforms.

The paper proceeds as follows. In Section 2, we describe market deregulation in Colombia in the nineties. In Section 3, we set up the building blocks for the estimation framework of labor and capital adjustments under non-convex adjustment costs. In Section 4, we de-

\footnotetext{
${ }^{2}$ One limitation of the AMS data is that plants do not report information on hours worked, so we use information for hours at the sector-level.
} 
scribe the data. In Section 5, we present evidence on non-linearities and interdependence in factor adjustments in Colombia, and on the response of these adjustments after the Colombian market reforms of 1990. In Section 6, we examine the effects on productivity due to increased reallocation from the removal of frictions in factor markets. We conclude in Section 7.

\section{Market Deregulation in Colombia}

In the early 1990s, the government of President Cesar Gaviria introduced important reforms to eliminate rigidities in factor and product markets. Law 50 of December 1990 introduced severance payments savings accounts and reduced dismissal costs by between $60 \%$ and $80 \%$ (see, e.g., Kugler (1999, 2005)). In 1993, Law 100 changed the social security system by allowing voluntary transfers from a pay-as-you-go system to a fully-funded system with individual accounts, while at the same time increasing contributions (see, e.g., Kugler and Kugler (2009)).

Other reforms sought to reduce frictions in financial markets. In 1990, Law 45 eliminated interest rate ceilings as well as requirements to invest in government securities, and lowered reserve requirements. At the same time, supervision of financial markets was reinforced in line with the Basle Accords for capitalization requirements. Law 9 of 1991 abolished exchange controls, thus eliminating the monopoly of the central bank on foreign exchange transactions and substantially reducing capital controls. Finally, Resolution 49 of 1991 eliminated restrictions to foreign direct investment. This resolution established national treatment of foreign enterprises and eliminated limits on the transfer of profits abroad (see, e.g., Kugler (2006)). The policy change stimulated capital inflows and increased competition in all sectors, but in particular in the financial sector.

At the same time, the Gaviria government continued the reduction in tariffs initiated by the preceding government. Effective protection came down from $62.5 \%$ in 1990 to $26.6 \%$ in 1991 (Edwards (2001)). In the late 1990s, the Samper government also made some progress in the areas of privatization and tax reform, though reforms in these areas were minor relative to those in factor markets and trade (Lora (2001)).

If factor market reforms achieved the goal of eliminating rigidities, we should observe changes in employment and capital adjustments after the reforms. In what follows, we consider the dynamics of factor adjustments before and after the reforms (pre- and post1990), allowing for interdependence between employment growth and investment. 


\section{Theoretical Framework}

This section explains the methodology we use to estimate adjustment hazards, as a function of gaps between actual and desired levels of labor and capital, in the presence of either convex or non-convex adjustment costs. In turn, we propose a framework for deriving the desired factor demands, which are needed to estimate these factor gaps.

\subsection{Inter-related Adjustment Costs}

Following Caballero, Engel and Haltiwanger (1995, 1997) (CEH hereafter), our theoretical framework is based on the observation that employment and capital are unlikely to equal their desired levels when they are subject to adjustment costs, where such costs can be related to regulations or technological frictions. In the presence of costs of adjusting employment and capital, thus, plant $j$ will face expected employment and capital shortages, $E\left(Z_{j t}\right)$ and $E\left(X_{j t}\right)$ at time $t$. We measure expected employment and capital shortages by

$$
E\left(Z_{j t}\right)=\frac{L_{j t}^{*}-L_{j t-1}}{\frac{1}{2}\left(L_{j t}^{*}+L_{j t-1}\right)} \quad \text { and } \quad E\left(X_{j t}\right)=\frac{K_{j t}^{*}-K_{j t-1}}{\frac{1}{2}\left(K_{j t}^{*}+K_{j t-1}\right)}
$$

where $L_{j t}^{*}$ and $K_{j t}^{*}$ are the desired level of employment and capital and $L_{j t-1}$ and $K_{j t-1}$ are employment and capital levels after shocks have occurred but before the plant has adjusted. Desired levels are those the plant would choose if adjustment costs are momentarily removed.

We define adjustment functions for employment and capital, $A_{j t}\left(E\left(Z_{j t}\right), E\left(X_{j t}\right)\right)$ and $B_{j t}\left(E\left(Z_{j t}\right), E\left(X_{j t}\right)\right)$, as the fraction of the respective expected shortage that is actually adjusted, and model them as a function of $E\left(Z_{j t}\right)$ and $E\left(X_{j t}\right)$. That is, defining the actual adjustments of employment and capital as:

$$
\triangle l_{j t}=\frac{L_{j t}-L_{j t-1}}{\frac{1}{2}\left(L_{j t}+L_{j t-1}\right)} \quad \text { and } \quad \triangle k_{j t}=\frac{K_{j t}-K_{j t-1}}{\frac{1}{2}\left(K_{j t}+K_{j t-1}\right)},
$$

the adjustment functions $A_{j t}\left(E\left(Z_{j t}\right), E\left(X_{j t}\right)\right)$ and $B_{j t}\left(E\left(Z_{j t}\right), E\left(X_{j t}\right)\right)$, which are also called "adjustment hazards" in the literature, are given by

$$
A_{j t}\left(E\left(Z_{j t}\right), E\left(X_{j t}\right)\right)=\frac{\triangle l_{j t}}{E\left(Z_{j t}\right)} \quad \text { and } \quad B_{j t}\left(E\left(Z_{j t}\right), E\left(X_{j t}\right)\right)=\frac{\triangle k_{j t}}{E\left(X_{j t}\right)} .
$$

The shapes of adjustment functions provide information about the nature of adjustment costs. ${ }^{3}$ Employment and capital adjustment functions independent of the shortages would

\footnotetext{
${ }^{3}$ Cooper and Willis (2003) raise questions about the use of measures of the gap between desired and
} 
be consistent with quadratic adjustment costs or a partial adjustment model. By contrast, employment and capital adjustment functions that depend on $E(Z)$ and $E(X)$, respectively, would be consistent with linear or lumpy adjustment costs or non-convexities (Caballero and Engel $(1993,1999))$. A key methodological contribution of our work is that we allow the adjustment function of one factor to depend on the gap of the other factor. ${ }^{4}$ We estimate parametric adjustment functions as follows:

$$
\begin{aligned}
& A_{j t}\left(E\left(Z_{j t}\right), E\left(X_{j t}\right)\right)=\lambda_{0}+\lambda_{1}\left[E\left(Z_{j t}\right)\right]^{2}+\lambda_{2} E\left(Z_{j t}\right) \times E\left(X_{j t}\right)+\lambda_{3}\left[E\left(X_{j t}\right)\right]^{2}, \\
& B_{j t}\left(E\left(Z_{j t}\right), E\left(X_{j t}\right)\right)=\kappa_{0}+\kappa_{1}\left[E\left(X_{j t}\right)\right]^{2}+\kappa_{2} E\left(Z_{j t}\right) \times E\left(X_{j t}\right)+\kappa_{3}\left[E\left(Z_{j t}\right)\right]^{2} .
\end{aligned}
$$

We modify this specification to permit asymmetric responses to shortages and surpluses, and to allow adjustments to vary between the pre- and post-reform periods. Since adjustment functions are poorly defined in the neighborhood of $E\left(Z_{j t}\right)=0$ and $E\left(X_{j t}\right)=0$, we re-write the adjustment function definitions and estimate the following equations at the micro-level with plant-level effects:

actual factors to make structural inferences about the presence and magnitude of non-convexities. They are concerned in part with the approximations of shortages made by CEH (1997) given data limitations. In contrast to $\mathrm{CEH}$, our results use a semi-reduced form specification allowing actual factor adjustment, of which we have direct measures for all factors, to be a non-linear function of fundamentals (TFP and demand shocks). We are able to measure those fundamentals at the plant-level.

${ }^{4}$ The only two previous studies of joint factor adjustment using micro-data that we know of are Polder, Pfann and Letterie (2004) and Bloom (2007). Polder et al. (2004) assume labor adjustment to be subject to convex adjustment costs. Their estimates of labor adjustment costs are extremely high (in their view, even implausibly high), leaving little room for interaction with capital adjustment. The paper by Bloom (2007) provides a structural framework to jointly estimate adjustment costs of labor and capital. Since our framework is semi-parametric, we are able to consider flexible specifications that can be estimated directly from the plant-level data. In contrast, Bloom (2007) uses simulated method of moments methods with moments from a variety of sources. It would be interesting in future work to consider a structural approach along the lines of Bloom (2007) and Cooper and Haltiwanger (2006) for the issues explored in this paper. One interesting aspect of the structural approach with indirect inference explored by Bloom (2007) is to take into account time aggregation effects. Here we are assuming the decision period is a year. However, our approach is robust to aggregation of "zero" adjustment episodes not only over time but also across production activities and types of capital, unlike structural approaches which rely on observation of non-adjustment events. 


$$
\begin{aligned}
\triangle l_{j t}\left(E\left(Z_{j t}\right), E\left(X_{j t}\right)\right) & =E\left(Z_{j t}\right) \times A_{j t}\left(E\left(Z_{j t}\right), E\left(X_{j t}\right)\right) \\
& =E\left(Z_{j t}\right) \times\left[\lambda_{0}+\lambda_{1}\left[E\left(Z_{j t}\right)\right]^{2}+\lambda_{2} E\left(Z_{j t}\right) \times E\left(X_{j t}\right)+\lambda_{3}\left[E\left(X_{j t}\right)\right]^{2}\right], \\
\Delta k_{j t}\left(E\left(Z_{j t}\right), E\left(X_{j t}\right)\right) & =E\left(X_{j t}\right) \times B_{j t}\left(E\left(Z_{j t}\right), E\left(X_{j t}\right)\right) \\
& =E\left(X_{j t}\right) \times\left[\kappa_{0}+\kappa_{1}\left[E\left(X_{j t}\right)\right]^{2}+\kappa_{2} E\left(Z_{j t}\right) \times E\left(X_{j t}\right)+\kappa_{3}\left[E\left(Z_{j t}\right)\right]^{2}\right] .
\end{aligned}
$$

In the estimation, we weight the adjustment functions by establishment employment and capital stock participation, respectively, to account for the greater importance of adjustments of large relative to small plants in determining aggregate adjustment.

To estimate shortages and adjustment functions, we first obtain the desired levels of employment and capital. We begin by estimating frictionless levels of employment and capital using the first-order conditions of the plants' static optimization problem, as described below. Since these frictionless demands will differ from the actual desired demands because the latter arise when adjustment costs are removed only momentarily, we make an adjustment assuming that desired demands are proportional to frictionless demands as in CEH (1995). In particular, we assume that the desired and frictionless levels relate to each other as follows: ${ }^{5}$

$$
\begin{aligned}
L_{j t}^{*} & =\bar{L}_{j t} \theta_{L j}, \\
K_{j t}^{*} & =\bar{K}_{j t} \theta_{K j},
\end{aligned}
$$

where $\bar{L}_{j t}$ and $\bar{K}_{j t}$ are the frictionless demands of employment and capital, and $\theta_{L j}$ and $\theta_{K j}$ are plant-specific employment and capital constants. We describe the estimation of these plant-specific constants below.

\subsection{Frictionless Profit Maximization}

We obtain frictionless levels of factor demands by solving the plants' optimization problem in the absence of adjustment costs. The plant's production function is:

$$
Y_{j t}=K_{j t}^{\alpha}\left(L_{j t} H_{j t}\right)^{\beta} E_{j t}^{\gamma} M_{j t}^{\phi} V_{j t},
$$

where $K_{j t}$ is capital, $L_{j t}$ is employment, $H_{j t}$ are hours per worker, $E_{j t}$ is energy use, $M_{j t}$ are materials, and $V_{j t}$ is a productivity shock.

\footnotetext{
${ }^{5}$ Bertola and Caballero (1994) show how this assumption is consistent with profit maximization in the presence of adjustment costs.
} 
There is an inverse demand for the product given by:

$$
P_{j t}=Y_{j t}^{-\frac{1}{n}} D_{j t}
$$

where $P_{j t}$ is the output price and $D_{j t}$ is a demand shock and where $-\frac{1}{\eta}$ is the inverse of the elasticity of demand.

Finally, the firm faces competitive factor markets, where total labor costs, capital costs, energy costs and materials costs are:

$$
\begin{aligned}
\omega_{L}\left(L_{j t}, H_{j t}\right) & =w_{0 t} L_{j t}\left(1+w_{1 t} H_{j t}^{\delta}\right) \\
\omega_{K}\left(K_{j t}\right) & =R_{t} K_{j t} \\
\omega_{E}\left(E_{j t}\right) & =P_{E t} E_{j t} \\
\omega_{M}\left(M_{j t}\right) & =P_{M t} M_{j t}
\end{aligned}
$$

The wage function depends on the straight-time wage, $w_{0 t}$, as well as on the overtime premium $w_{1 t}$. The firm takes the user cost of capital, $R_{t}$, and energy and material prices, $P_{E t}$ and $P_{M t}$, as given.

The firm maximizes frictionless profits by choosing capital, employment, hours, energy consumption, and materials, ignoring adjustment costs. The solution to the system of firstorder conditions is given by a system of five equations that can be solved numerically in terms of fundamentals (technology, demand, cost parameters, input prices, and shocks). ${ }^{6}$ As we describe below, the rich plant-level data permit us to estimate the fundamentals, the frictionless demands and, in turn, the desired demands for capital and labor.

\section{Estimation of Desired Factor Demands}

To estimate the frictionless levels of employment and capital numerically, we need to obtain the parameters, $\alpha, \beta, \gamma, \phi, \eta$, and $\delta$ as well as productivity and demand shocks, $\widetilde{V}_{j t}$ and $\widetilde{D}_{j t}$, and input prices, $\widetilde{R}_{t}, \widetilde{w}_{0 t}$, and $\widetilde{w}_{1 t}$. We estimate factor elasticities $(\alpha, \beta, \gamma, \phi)$ using cost-shares calculated at the aggregate level. ${ }^{7}$ In turn, we use those estimates to calculate $\widetilde{V}_{j t}$ as a residual from the (log) production function. Following Eslava et al. (2004), we then

\footnotetext{
${ }^{6}$ The full set of five equations is reported in the Methodological Web Appendix.

${ }^{7}$ We use aggregate cost-shares which enables us to easily consider a range of robustness checks including estimation of IV-based factor elasticites (from Eslava et al. 2004), only available at the aggregate level. However, results are robust to the use of sector-level factor elasticities obtained with a cost-shares approach. When factor elasticities obtained with IV methods are used, results are also similar to those reported here. See the Methodological Web Appendix for details.
} 
estimate the inverse demand function, using $\widetilde{V}_{j t}$ as an instrument, to obtain the demand elasticity $(\eta)$ and a measure of the demand shock, constructed as the (log) residual of the demand estimation. ${ }^{8}$ For the estimations of factor and demand elasticities we need data on production, factor use, and output prices at the plant level.

Our data come from the Colombian Annual Manufacturers Survey (AMS) for the years 1982 to 1998. The AMS is an unbalanced panel of Colombian plants with more than 10 employees, or sales over US\$35,000 in 1998. The AMS includes information on: the value of output and average prices charged for each product manufactured; overall cost and average prices paid for each material used in the production process; energy consumption in physical units and average energy prices; production and non-production number of workers and payroll; book values of equipment and structures; and 5-digit ISIC industry classification codes. $^{9}$

We construct our measures of physical output and materials by dividing revenue and material expenditures by plant-level output and materials deflators. By using plant-level prices on output and materials, we eliminate a common source of measurement error in productivity measures. Energy consumption is directly reported by the plant. We construct the plant capital stock recursively using a perpetual inventory method. Finally, since the AMS does not have data on hours, we construct a measure of hours per worker at time $t$ for sector $G(j)$, by dividing sector earnings per worker from AMS data by a measure of sectoral wages at the 3-digit level from the Monthly Manufacturing Survey, and then deflating the nominal wage with the CPI. ${ }^{10}$

Since the AMS does not contain information on the user cost of capital and labor costs, we collect information on these from additional sources. For the user cost of capital, $\widetilde{R}_{t}$, the results we report use a constant value, 0.15, which is in the lower bound of previous estimates for Colombia. ${ }^{11}$ The straight-time wage, $\widetilde{w}_{0 t}$, is a sector-level wage calculated

\footnotetext{
${ }^{8}$ Besides differences in market power, the residual from this inverse-demand regression may also capture relative price shocks due to differences in product quality across plants. Quality differences are, thus, also embedded in our measures of desired employment and capital stocks.

${ }^{9}$ See Eslava et al. (2004) for a more detailed description of the data.

${ }^{10}$ By using a sectoral wage index, we are attributing plant-specific differences in wages from the sectoral average to differences in labor quality at the plant.

${ }^{11}$ We tried other estimates of $\widetilde{R}_{t}$, both constant and variable, which yield similar results, although some of them are less reliable. Since the user cost of capital used in our analysis was obtained with actual data in the presence of frictions, we try a lower value of $\widetilde{R}_{t}=0.08$ and find the results are virtually identical. In addition, we tried using the real interest rate instead of the user cost of capital estimated in previous studies and the results for labor adjustments are similar but the capital adjustment hazard turns out negative for capital surpluses, suggesting that this measure introduces substantial measurement error. Details on these
} 
as explained above and the overtime premium, $\widetilde{w}_{1 t}$, is set to the legally required overtime premium of $25 \%$ in Colombia. We use $\delta=2$, which is estimated for the U.S. by both Bils (1987) and Cooper and Willis (2003). ${ }^{12}$

Given the parameters and shocks, we estimate desired demands for capital and labor as follows. ${ }^{13}$ First, we solve numerically the full five equation system of frictionless first-order conditions for all factors, in terms of the fundamentals for each plant-year observation. Second, we exploit identities derived from the first-order conditions for the variable factors (materials, energy and hours) with and without assuming frictions for variable factors. These identities imply that frictionless demand for a factor is equal to actual demand for a factor times the ratio of frictionless revenue to actual revenue. We use these identities and our initial numerical solution to the system of first order equations to generate measures of the variable factors in the frictionless environment. ${ }^{14}$ Third, we express frictionless capital and labor as functions of fundamentals and the frictionless variable factors (estimated as just described). That is, we use the following relationships, obtained from the full system of first order conditions:

$$
\begin{aligned}
\widetilde{\bar{L}}_{j t} & =\frac{\frac{\eta}{\eta-1}\left[\ln \left(\frac{\eta}{\eta-1}\right)-\widetilde{D}_{j t}\right]-\widetilde{V}_{j t}-\beta \widetilde{\bar{H}}_{j t}-\gamma \widetilde{\bar{E}}_{j t}-\phi \widetilde{\bar{M}}_{j t}+\left(\frac{\eta}{\eta-1}-\alpha\right)\left[\widetilde{w}_{0 t}+\ln \left(1+w_{1 t} \bar{H}_{j t}^{\delta}\right)-\ln \beta\right]-\alpha \ln \alpha+\alpha \widetilde{R}_{t}}{\left[\alpha+\beta-\frac{\eta}{\eta-1}\right]}, \\
\widetilde{\bar{K}}_{j t} & =\frac{\frac{\eta}{\eta-1}\left[\ln \left(\frac{\eta}{\eta-1}\right)-\widetilde{D}_{j t}\right]-\widetilde{V}_{j t}-\beta \widetilde{\bar{H}}_{j t}-\gamma \widetilde{\bar{E}}_{j t}-\phi \overline{\bar{M}}_{j t}+\left(\frac{\eta}{\eta-1}-\beta\right)\left[\widetilde{R}_{t}-\ln \alpha\right]-\beta \ln \beta+\beta\left[\widetilde{w}_{0 t}+\ln \left(1+w_{1 t} \bar{H}_{j t}^{\delta}\right)\right]}{\left[\alpha+\beta-\frac{\eta}{\eta-1}\right]},
\end{aligned}
$$

where $\widetilde{y}$ denotes the natural logarithm of variable $y$.

As a final step, we estimate the plant-specific constant factors of proportionality relating frictionless to desired demands for capital and labor, as described above. Following CEH (1995), we estimate the plant-specific constants using periods when desired capital and labor are plausibly close to actual capital and labor. As described in the Methodological Web Appendix, we consider a number of alternative ways of classifying such periods and find our results are robust to reasonable alternatives. For the baseline results reported in the paper we estimate these plant-specific constants using the ratios between the actual and the frictionless employment and capital levels for the year in which the plant is at its

robustness tests, as well as the corresponding results, are presented in the Methodological Web Appendix.

${ }^{12}$ We tried different values of $\delta$. For example, a higher value of $\delta=3$ suggests very similar results. See the results in the Methodological Web Appendix.

${ }^{13}$ See the Methodological Web Appendix for a more detailed description.

${ }^{14}$ In this second step, we also include a constant plant-specific correction factor to allow for plantspecific fixed effects in the measurement error of frictionless revenue. The impact of these multiple steps is modest. For example, the correlation between the first step estimate of materials and the final step estimate of materials is 0.99 . 
median employment growth and investment, respectively. ${ }^{15}$

Table 1 presents descriptive statistics of quantities and prices, weighted by output, and of productivity and demand shocks, for the pre- and post-reform periods. Quantity variables are expressed in logs and prices are relative to a yearly producer price index to discount inflation. Output and factor use increased between the pre- and post-reform periods. Relative prices of output and materials prices declined between the pre- and postreform periods, while energy prices and wages increased. Average productivity and the dispersion of productivity went up during the reform period. While demand shocks fell on average, their dispersion increased after the reforms. Both productivity and demand shocks are very persistent, i.e., they have an $\mathrm{AR}(1)$ coefficients of around 0.92 and $0.98 .{ }^{16}$

Table 1 also presents output-weighted first and second moments of the distributions of labor and capital shortages, which are used to estimate adjustment functions, for the sample of pairwise continuers (i.e., all plants that are present in $t-1$ and $t$ ). ${ }^{17}$ Mean capital shortages move closer to zero in the post-reform period, while mean labor shortages and the standard deviations of both shortages do not change much between the two periods.

\section{$5 \quad$ Labor and Capital Adjustments}

\subsection{Adjustment Functions}

Table 2 presents estimates of the weighted labor and capital adjustment functions (Columns (1)-(6), and Columns (7)-(12), respectively). As a benchmark, we report results from a

\footnotetext{
${ }^{15}$ When there is more than one year in which a plant is at its median growth, we calculate the mean ratio between the actual and the frictionless levels of factor use for all such years. Our results are robust to using the median of those ratios rather than using the mean. They are also robust to defining $\theta_{L j}$ and $\theta_{K j}$ not as ratios for the median adjustment year, but as the mean of ratios over a number of years closest to the median adjustment, where the number of years used depends on the number of years a plant is present in the sample. A more detailed description of robustness tests is included in the Methodological Web Appendix.

${ }^{16}$ The persistence of TFP looks very similar if we use sector-level instead of plant-level prices. The first-order autocorrelation of TFP calculated using sector-level prices is 0.9 . The finding that persistence is about the same whether one uses physical TFP as here or revenue TFP (with sectoral prices) is consistent with the patterns of persistence found by Foster, Haltiwanger, and Syverson (2008) for the U.S. Note however the estimated persistence in Colombia is higher than that estimated for the U.S.. However, for the U.S. demand shocks are estimated to have higher persistence than TFP, just as found here.

${ }^{17}$ We have also estimated our results using only a balanced panel. The results for the hazards and the effects of reforms are similar to those shown below, with the exception that nonlinear adjustment patterns are even more pronounced. See Methodological Web Appendix.
} 
standard partial adjustment model (PAM), in which changes in labor and capital are independent of the magnitude and sign of shortages, so that establishments always close a constant fraction of the gap. Comparing the results of this specification in Columns (1) and (7) to those of models that include own shortages in Columns (3) and (9) show that the adjusted $R^{2} s$ increase from 0.1799 to 0.1958 for labor adjustment and from 0.2093 to 0.2647 for capital adjustment. The non-linear terms as well as the terms capturing asymmetries for positive and negative shortages are not only economically but also individually and jointly statistically significant, with F-statistics of 410.05 and 1,560.05 for labor and capital adjustments, respectively. A standard linear PAM specification would, thus, miss key aspects of the adjustment process captured by our flexible non-linear and asymmetric specification.

Figures 1 and 2 show the weighted employment and capital adjustment hazards, each as a function of the respective shortage (left scale). Figures 1 and 2 also show the fractions of employment and of the capital stock for plants with different shortages (right scale). We focus attention on the region of shortage distributions where most plants are located, by truncating these figures at shortages of -1.35 and $1.35 .{ }^{18}$ Figures 1 and 2 show highly nonlinear adjustments. The figures show that job creation and capital creation and destruction increase as the magnitude of the shortages and surpluses increases.

Figures 1 and 2 also show that there are striking asymmetries between positive and negative adjustments. Figure 1 shows that labor adjustment is a highly non-linear function of the gap when faced with employment shortages, but less so when faced with surpluses. This may be because one of the most important costs of separations are severance payments imposed by regulations, which are per worker costs as opposed to fixed costs. By contrast, we find strong non-linearities on both the capital creation and destruction sides. At the same time, we find clear evidence of irreversibilities for capital on the destruction side, as capital shedding is much less likely than investment.

These results are consistent with the findings in CEH $(1995,1997)$ for the U.S. who find evidence of non-linear adjustment for capital and employment separately. Moreover, the finding of irreversibility in capital formation is consistent with the evidence by Caballero and Engel (1999) and Cooper and Haltiwanger (2006) who find that convex and nonconvex costs of adjusting, as well as irreversibilities, are all important components of capital adjustment cost functions in the U.S.

Yet, our specifications are more general than those in previous studies, since we consider

\footnotetext{
${ }^{18}$ About $96 \%$ of aggregate employment and $90 \%$ of the aggregate capital stock are concentrated in these regions.
} 
joint adjustments of employment and capital, allowing us to study the effects of capital shortages on employment adjustment and of employment shortages on capital adjustment. Comparing the standard non-linear model with non-linear models that include shortages of the other factors suggests that interactions indeed matter. Results from models that include cross-terms in Columns (5) and (11) show that the cross-terms are individually as well as jointly significant, with F-statistics of 33.59 and 205.7 for labor and capital, respectively. The $R^{2}$ also goes up relative to the standard PAM and non-linear models. The importance of cross-effects is illustrated in Figures 1 and 2. The solid line shows the adjustment function when the shortage of the other factor is set to zero, while the heavy continuous/discontinuous dashed lines show the adjustment functions when the shortage of the other factor is set to +/- one standard deviation. Figures 1 and 2 show that capital shortages reduce job creation, while labor surpluses reduce capital destruction. These results suggest adjustment complementarities in the sense that frictions to adjusting one margin reinforce frictions on the other margin. ${ }^{19}$ Also, note that not including interaction effects in the estimation (light dotted lines in both Figures) leads to somewhat flatter estimated hazards in job creation and capital destruction. However, the primary implication of including interaction effects is that such effects yield interesting interactions and not so much that the estimation of the own effects are impacted by the inclusion of interaction effects.

Another advantage of our approach, compared to those of previous studies, is the use of plant-level prices. Plant-level prices for outputs and inputs allow us to separate physical productivity and demand shocks. Thus, the use of plant-level prices yields better measures of fundamentals, which are needed to construct our measures of shortages and surpluses. We have conducted an alternative analysis presuming we only had access to sector-level output, energy, materials prices in the estimation of our fundamentals (see Methodological Web Appendix for details). Using only sectoral-level prices, we obtain less precise estimates of the adjustment hazards as well as patterns that are consistent with substantial measurement error. For instance, we obtain negative capital adjustment hazards in the capital destruction side, and a decreasing adjustment function in the creation side. Both patterns are consistent with measurement error that induces mismeasurement of desired factors and, in turn, factor adjustment gaps. In addition, we find that employment and capital adjustment hazards based on measures of fundamentals that do not use plant-level prices shift down after reforms. Thus, the measurement error induced by using sectoral-level prices would yield misleading inferences about the impact of reforms as well as about the shape of

\footnotetext{
${ }^{19}$ However, adjustment complementarities do not hold symmetrically over shortages or surpluses.
} 
the adjustment hazards. ${ }^{20}$ Moreover, if we had only had data on sectoral-level prices, it would be impossible to undertake the analysis of changes in allocative efficiency reported in Section 6.

\subsection{Adjustments after Deregulation}

The even-numbered Columns of Table 2 present results which allow for differential effects of the reforms in the PAM, the standard non-linear model and the non-linear model with cross-terms. In all cases, the post-reform terms are jointly significant. To better see the role of reforms on adjustment dynamics, Figures 3 and 4 show employment and capital adjustment hazards before and after reforms, as a function of the respective shortage.

Figure 3 shows that the job destruction hazard almost doubled after the labor market reform of 1990. On the creation side, there is slightly less adjustment for small shortages but more for large shortages. Non-linearities became more important on the job creation and job destruction sides, suggesting that reforms increased the relative importance of adjustment costs that yield nonlinearities (e.g., fixed costs).

Figure 4 shows large differences in terms of the impact of reforms on the creation and destruction of capital. There is less capital destruction after the reforms. ${ }^{21}$ By contrast, for a broad range of values of capital shortages, the responsiveness of investment increases after the reforms. Moreover, the effect of reforms on investment is non-linear, as the adjustment function becomes flatter. Investment becomes less responsive to very large capital shortages after the reforms, but this decreased flexibility has little aggregate impact given that the share of capital facing shortages above 1 is less than $10 \%$.

The greater responsiveness of capital adjustment to shortages and the flatter shape of the adjustment function in this range are consistent with reforms reducing adjustment costs of investment. However, less adjustment to capital surpluses after the reforms is at odds with the expectation of greater flexibility in capital destruction. The greater irreversibility may reflect a substitution towards job destruction and away from capital destruction. This may be because reforms made it relatively cheaper to dismiss workers, so that after the reforms firms used capital destruction less readily due to the presence of technological and market barriers. In fact, the effect of reforms in the shape of the adjustment function for

\footnotetext{
${ }^{20}$ Without plant-level prices, we cannot estimate productivity and demand shocks, so we focus on a more general profitability shock, and we impose a given demand elasticity. Greater detail on how adjustment functions were estimated in the absense of plant-level prices can be found in the Methodological Appendix.

${ }^{21}$ This finding is robust to using a measure of the user cost of capital that varies over time, or one that is fixed at a level below that of our basline results.See the Methodological Web Appendix.
} 
capital mirrors the effect we obtain for the employment adjustment function. We also note that the patterns of the capital adjustment functions after the reforms more closely mimic those of the U.S. (see Caballero, Engel and Haltiwanger (1995)). One way of thinking about the latter is that the reforms may have increased the relative importance of technologyrelated frictions relative to institutional frictions. An open question for future research is to identify precisely the institutional frictions that yielded the pre-reform patterns of adjustment.

\section{Factor Reallocation and Aggregate Productivity}

In this section, we examine the potential productivity gains from removing frictions to factor adjustment, and whether there were actual productivity gains associated with the changes in labor and capital adjustments observed in Colombia after the reforms. In particular, we measure changes in aggregate productivity due to changes in reallocation from the reduction or removal of frictions in factor markets. We do this by conducting an Olley and Pakes (1996) decomposition, which quantifies what part of aggregate productivity every year reflects the productivity of the average plant and what part captures the concentration of activity in the more productive plants:

$$
T F P_{t}=\overline{T F P}_{t}+\sum_{j=1}^{J}\left(f_{j t}-\overline{f_{t}}\right)\left(T F P_{j t}-\overline{T F P}_{t}\right),
$$

where $T F P_{t}$ is the aggregate total factor productivity measure for a given 3-digit manufacturing sector in year $t$. These aggregate measures correspond to weighted averages of our plant-level TFP measures, where the weights are market shares (calculated as described below). The first term of the decomposition, $\overline{T F P}_{t}$, is the average cross-sectional (unweighted) mean of total factor productivity across all plants in that sector in year $t$. $T F P_{j t}$ is the total factor productivity measure of plant $j$ at time $t$ estimated as described in Section $5, f_{j t}$ is the share or fraction of plant $j^{\prime} s$ output out of sectoral output at the 3 -digit level in year $t$, and $\bar{f}_{t}$ is the cross-sectional unweighted mean of $f_{j t}$ for the sector. ${ }^{22}$ The second term in this decomposition allows us to understand whether production is

\footnotetext{
${ }^{22}$ The fact that we calculate aggregate measures at the sector level means that our focus is on withinsector reallocation rather than between-sector reallocation, for sectors defined at the 3-digit level. In the results, we report averages of the 3-digit level results using time invariant industry average gross output shares to aggregate across industries so our results don't reflect changes in the industry composition over time.
} 
disproportionately located at high-productivity plants, and examining this decomposition over time allows us to learn whether the cross-sectional allocation of activity changed in response to market reforms. ${ }^{23}$

We estimate the actual decomposition of TFP and then we construct four counterfactuals, which allow us to answer what would had been the cross-sectional allocation had frictions in factor markets been removed altogether or, alternatively, had they been reduced to the post-reform levels. The decompositions only differ from each other in the shares used in the second term. The first decomposition uses actual output shares. The other decompositions use counter-factual output shares, where output is calculated as:

$$
\widehat{Y}_{j t}=\widehat{K}_{j t}^{\widehat{\alpha}}\left(\widehat{L}_{j t} \widehat{H}_{j t}\right)^{\widehat{\beta}} \widehat{E}_{j t}^{\gamma} \widehat{M}_{j t}^{\phi} \widehat{V}_{j t}
$$

In each case, $\widehat{V}_{j t}$ is the exponential of our TFP measure. The levels $\widehat{M}_{j t}, \widehat{E}_{j t}, \widehat{H}_{j t}, \widehat{K}_{j t}$, and $\widehat{L}_{j t}$, however, vary across decompositions. For the second decomposition, $\widehat{M}_{j t}, \widehat{E}_{j t}, \widehat{H}_{j t}$, $\widehat{K}_{j t}$ and $\widehat{L}_{j t}$ are the frictionless levels of these factors. ${ }^{24}$ For other decompositions, $\widehat{M}_{j t}$, $\widehat{E}_{j t}$, and $\widehat{H}_{j t}$ are the observed levels, while $\widehat{K}_{j t}$ and $\widehat{L}_{j t}$ vary across the different exercises. For the third decomposition, $\widehat{K}_{j t}$ and $\widehat{L}_{j t}$ are the capital and employment levels that would have resulted if labor and capital changed according to our estimated adjustment functions in equation system (3), which vary between the pre- and post-reform periods. Finally, for the last two decompositions, we construct counter-factual shares where $\widehat{L}_{j t}$ and $\widehat{K}_{j t}$ are the employment and capital levels that would have prevailed if the labor and capital adjustment functions, respectively, had remained the entire period as during the pre-reform years. $^{25}$

Figure 5 presents the results of these decompositions. The solid line corresponds to the $\overline{T F P}_{t}$ term (equal across the different versions of the decomposition), while the other lines represent the second term, named "cross-term" using shares from the different measures of output. The cross-term of the actual decomposition, represented by the dotted line, shows that allocative efficiency improved after the introduction of reforms in 1991, increasing aggregate productivity.

\footnotetext{
${ }^{23}$ An advantage of this cross-sectional method over methods that decompose changes in productivity over time, is that cross-sectional differences in productivity are more persistent and less dominated by measurement error or transitory shocks.

${ }^{24}$ For all counter-factuals, we estimate the levels of capital and labor, and thus their respective adjustments, holding the demand shocks at their average level for each plant.

${ }^{25}$ The projected growth rates for the counterfactuals which use our estimated adjustment functions are in the $(-2,2)$ range for all observations. This is an indication of good fit of our adjustment functions.
} 
The thick grey line presents the cross-term of the frictionless decomposition, which shows what productivity levels would have been had all frictions in factor adjustment been removed. Comparing this line with the cross-term of the actual decomposition shows that productivity would have been substantially higher in all years had all frictions from factor markets been removed. The difference is quite large: the actual cross-term is between 20 and $25 \mathrm{log}$ points lower than it would be in the absence of barriers to efficient allocation. This increase in productivity results because allowing plants to adjust labor and capital more easily increases the market share of more productive plants and reduces the share of less productive plants.

The remaining counter-factual decompositions allow answering whether the Colombian reforms moved the economy in the direction of a frictionless environment. From Figure 5, it is clear that the impact of reforms on aggregate productivity via reductions in adjustment frictions is small. The cross-term is almost identical between the decomposition that uses output projected by our adjustment function (in circles in the Figure) and those that use output projected by keeping one or both of the adjustment functions at its pre-reform level. However, as would be expected, the impact of the reduction in adjustment frictions on productivity is positive. ${ }^{26}$

In interpreting the small contribution of the actual vs. potential reduction in adjustment frictions, it is useful to return to Figures 3 and 4 (and Table 2) to note the magnitudes of the actual changes in adjustment costs. We find changes that are on the order of magnitude of about a 10 percentage point increase in the fraction of the gaps that are closed for employment surpluses and capital shortages over ranges where most of the mass of the distribution lies. Such changes are economically and statistically significant but not large either in the sense of eliminating adjustment frictions or going from a situation of virtually no adjustment to substantially more rapid adjustment. The finding that removing all frictions would substantially increase productivity suggests that in the presence of large changes in the speed of adjustment we would observe a large increase in productivity from improved allocative efficiency. However, the correct inference is apparently that notable increases in productivity require large changes in the adjustment frictions. ${ }^{27}$

\footnotetext{
${ }^{26}$ One concern in interpreting these decompositions is that the reforms apparently yielded less flexibility in terms of capital destruction which may be offsetting the gains from greater flexibility for labor and for capital surpluses. However, one of our decompositions focuses only on the greater flexibility of labor and we still obtain modest effects.

${ }^{27}$ Hopenhayn and Rogerson (1992) find in their model calibration that eliminating adjustment costs in labor from severance payments that amount to one year of wages would increase productivity via allocative efficiency by about 2 percent. Our finding of an increase in productivity of $20 \log$ points from elimination
} 
It is also interesting to note that the actual decomposition, the frictionless decomposition and all of the remaining counterfactual decompositions show a substantial improvement in allocative efficiency following reforms. Thus, it does appear that reforms had an impact on allocative efficiency, possibly through channels other than the reduction in the costs of input reallocation. What might those other channels be? To consider this question, it is useful to compare the findings in this section with the recent literature examining the role of allocation distortions in accounting for productivity differences across countries and over time. Restuccia and Rogerson (2007), Banerjee and Duflo (2005), Eslava et al. (2004, 2006), Hsieh and Klenow (2006) and Bartelsman, Haltiwanger and Scarpetta (2006) all explore the idea that distortions to output and factor allocation may underlie productivity differences across countries and within countries over time. ${ }^{28}$ The working hypothesis from this literature is that allocative distortions prevent resources from being deployed to their highest valued use and this literature develops the underlying theory and related empirical analysis to explore this hypothesis.

Our findings contribute to this literature in a number of ways. First, given our ability to measure frictionless optimal capital and labor using our measures of fundamentals (i.e., productivity, demand and cost shocks), our analysis provides a direct metric for evaluating this hypothesis - that is, we are able to construct a measure of productivity associated with establishments moving to their optimal frictionless capital and labor decisions and we find that such movements have substantial potential for improving productivity. Second, the approach in this paper explores the view that the distortions to allocation from regulations in part take the form of increased factor adjustment costs. ${ }^{29}$ Third, in this respect while we show that the potential impact of removing all frictions is large, the actual reforms in Colombia in terms of reducing capital and labor adjustment costs only had a modest

of both capital and labor market adjustment costs is difficult to compare directly to the Hopenhayn and Rogerson finding but suggests considerably larger scope for productivity improvements from reducing adjustment frictions.

${ }^{28}$ From a positive stance, Banerjee and Duflo (2005) note that coexistence of high and low returns to investment opportunities, together with the low average marginal product of capital, suggests the misallocation of capital as a cause behind the low output per capita and capital per worker in developing countries. They provide evidence on sources of misallocation of capital, including credit constraints, institutional failures, and others. They conclude that "combined with multiple technological options and a fixed cost of upgrading to better technologies, a model based on misallocation of capital does quite well in terms of explaining the productivity gap."

${ }^{29}$ Caballero et al. (2004) also consider improvements in allocative efficiency through reductions in adjustment costs. 
impact on improved allocative efficiency. ${ }^{30}$

In considering potential alternative sources of misallocation (i.e., not driven by factor adjustment costs), Banerjee and Duflo (2005) and Hsieh and Klenow (2006) list, among others, local externalities, credit constraints, missing insurance markets and government failures. They also emphasize that increases in competitive pressures from market reforms provides less scope for the allocation of activity to be based on arbitrary and capricious factors. The widespread reforms discussed in Section 2 potentially reduced the misallocation from a number of these sources. As such, our finding of improved allocative efficiency that is apparently not driven by a reduction in factor adjustment costs is potentially driven by amelioration of one of those other sources highlighted by Banerjee and Duflo (2005) and Hsieh and Klenow (2006). Given the substantial gains in allocative efficiency over this period in Colombia, identification of the precise source of improvement is a promising area for future research. ${ }^{31}$ We also note in closing this section that these alternative sources of misallocation inherently yield more persistent misallocation relative to adjustment costs. A lesson of our analysis is that given that distorted adjustment costs yield less persistent misallocation it requires a very large change in the adjustment costs to have a notable impact on productivity.

\section{Conclusion}

In this paper, we examine how plant-level adjustment dynamics for capital and labor interact with each other. Given the widespread finding that plant-level adjustments are lumpy, we allow for non-linear adjustment dynamics. Beyond considering the interaction of capital and labor adjustments, we estimate adjustment dynamics in the context of an emerging economy, namely Colombia, that has undergone a substantial reform process intended to

\footnotetext{
${ }^{30}$ One impact of reforms that our current approach does not capture relative to this literature is that the improvement in allocative efficiency may be due to which firms and establishments survive. Instead, in this paper we focus on mitigating inefficiencies due to misallocation across continuing establishments. In Eslava et al. $(2004,2006)$ we have explored the impact of reforms on market selection. In future work, we plan to explore these two margins as well as the entry margin simultaneously.

${ }^{31}$ For example, it may be that trade reforms improved allocative efficiency as suggested in Eslava et al. (2004). Note also that Figure 5 suggests an increase in within plant productivity over the 1980s in a manner consistent with Fernandes (2007). Fernandes argues that the trade reforms over the 1980s contributed to this within plant increase in productivity via increases in competitive pressures on existing firms. However, our evidence which extends beyond the 1991 period analyzed by Fernandes shows that within plant productivity did not increase over the course of the 1990s - a time period of continued trade and other market reforms.
} 
deregulate factor markets.

Our results can be briefly summarized as follows. First, consistent with the existing literature, we find strong evidence of non-linear micro adjustments. Businesses are likely to adjust capital and labor by a proportionally greater amount if the gaps between desired and actual levels are large. Equivalently, we find larger proportionate responses to large TFP and demand and cost shocks than in response to small shocks. Second, we find important interactions between capital and labor adjustments. In particular, businesses with capital shortages are less likely to create jobs in response to labor shortages, and businesses with labor surpluses are less likely to shed capital when faced with capital surpluses. These findings highlight the importance of jointly analyzing capital and labor adjustments. In terms of policy, the evidence highlights a potentially undesirable feature of piecemeal reform, namely that frictions in still regulated factor markets can distort adjustment of a newly deregulated factor, thus hampering the effectiveness of reform.

Our analysis shows that most of the findings with regards to labor and capital adjustments would be missed if a standard linear partial adjustment model was used instead of the more flexible, non-linear, multivariate model. The linear partial adjustment model implies only that labor flexibility increases and capital flexibility decreases after the reforms and misses the asymmetries in labor and capital adjustments, as well as the asymmetric responses of these adjustments to the reforms. We also find that the availability of plant-prices to be used both as deflators and to measure cost shocks faced by the plant substantially reduces measurement error in the estimation of adjustment functions. Put differently, if plant-level prices had not been available, the resulting estimates would have yielded implausible results for the shape of the adjustment hazards, and misleading inferences about the impact of reforms.

In terms of the impact of market reforms, the largest effect we find is the increased flexibility of labor, especially on the destruction side, and of investment. Interestingly, this increase in labor flexibility is accompanied by a significant reduction in capital destruction. Thus, while the reforms may have succeeded in making labor more flexible in Colombia, contracting plants appear to have used that greater flexibility of labor to reduce capital adjustments. One possible explanation for this pattern is that the reduction in frictions from the institutional reform may increase the importance of technology-related frictions. Generally, technological frictions associated with labor rotation are smaller than those associated with retooling or scrapping capital. In the absence of distortions, producers would rather respond to shocks through the adjustment of labor, as the more variable factor, as opposed to through the adjustment of fixed capital. In fact, the adjustment 
function of capital after the Colombian reforms closely mimics those estimated for the U.S., suggesting that the Colombian capital adjustments may now be driven much more by technological and less by institutional factors as in the U.S.

If factor reallocation facilitates the expansion of more efficient incumbents and the contraction of less efficient plants, then we may expect market reforms to be associated with productivity growth. We, thus, explore whether the changes in employment and capital adjustments after the Colombian reforms were productivity-enhancing and whether the hypothetical move to a completely frictionless world in factor markets would be productivityenhancing. We find that moving towards frictionless factor adjustment would indeed increase productivity substantially (by more than 20 log points in any given year) by allowing the reallocation of activity from low towards high productivity plants. We also find substantial improvements in allocative efficiency in Colombia over the reform period. However, in spite of the potential for reductions in factor adjustment costs, our counterfactual analysis shows that not much of the actual improvement in allocative efficiency is due to the reductions in factor adjustment costs. Apparently, other aspects of the reforms yielded improvements in allocative efficiency. Note, however, that our findings show there is still substantial room for improvements in allocative efficiency from reductions in factor adjustment costs.

While our results suggest that the reforms generated efficiency gains, it is also important to note that the much greater adjustment in response to labor surpluses after the reforms may have also impacted the dynamics of unemployment in terms of inflows, outflows and the duration of unemployment. Assessing the impact on unemployment dynamics including the impact on workers is part of our intended future research. 


\section{Appendix}

This appendix reports details on the methodology used to calculate frictionless factor demands. It also shows the different tests used to explore the robustness of the baseline results to changes in some assumptions.

\section{A.1. First-order Conditions of Profit Maximization Problem}

This section reports the system of five equations characterizing frictionless factor demands, which results from the first order conditions of the profit maximization problem. Our assumptions on production and demand functions imply the following revenue function:

$$
\Lambda_{j t}=\left(K_{j t}^{\alpha}\left(L_{j t} H_{j t}\right)^{\beta} E_{j t}^{\gamma} M_{j t}^{\phi}\right)^{1-\frac{1}{\eta}} S_{j t},
$$

where the notation is as introduced in Eslava et al. (2008), and where,

$$
S_{j t}=V_{j t}^{1-\frac{1}{\eta}} D_{j t}
$$

is a measure of the "profitability shocks" received by the firm. It can be recovered (in log form) from:

$$
\widetilde{S}_{j t}=\widetilde{\Lambda}_{j t}-\left(1-\frac{1}{\eta}\right)\left[\alpha \widetilde{K}_{j t}+\beta \widetilde{H}_{j t}+\beta \widetilde{L}_{j t}+\gamma \widetilde{E}_{j t}+\phi \widetilde{M}_{j t}\right]
$$

where we have denoted $\widetilde{X} \equiv \ln X$. Defining:

$$
\zeta=\left(\frac{\eta}{\eta-1}\right)\left[\ln \left(\frac{\eta}{\eta-1}\right)-\widetilde{S}_{j t}\right]
$$

we obtain that the system of five first-order conditions of the profit maximization problem 
can be expressed as:

$$
\begin{aligned}
& \widetilde{\bar{K}}_{j t}= \frac{\zeta+\left(\frac{\eta}{\eta-1}\right)\left[\widetilde{R}_{t}-\ln \alpha\right]-\beta\left(\widetilde{\bar{L}}_{j t}+\widetilde{\bar{H}}_{j t}\right)-\gamma \widetilde{\bar{E}}_{j t}-\phi \widetilde{\bar{M}}_{j t}}{\left[\alpha-\left(\frac{\eta}{\eta-1}\right)\right]} \\
& \widetilde{\bar{L}}_{j t}=\frac{\zeta+\left(\frac{\eta}{\eta-1}\right)\left[\widetilde{w}_{0 t}+\ln \left(1+w_{1 t} \overline{\bar{H}}_{j t}^{\delta}\right)-\ln \beta\right]-\alpha \widetilde{\bar{K}}_{j t}-\beta \widetilde{\bar{H}}_{j t}-\gamma \widetilde{\bar{E}}_{j t}-\phi \widetilde{\bar{M}}_{j t}}{\left[\beta-\left(\frac{\eta}{\eta-1}\right)\right]} \\
& \widetilde{\bar{H}}_{j t}=\frac{\zeta+\left(\frac{\eta}{\eta-1}\right)\left[\widetilde{w}_{0 t}+\widetilde{w}_{1 t}+\widetilde{\bar{L}}_{j t}+\ln \delta-\ln \beta\right]-\alpha \widetilde{\bar{K}}_{j t}-\beta \widetilde{\bar{L}}_{j t}-\gamma \widetilde{\bar{E}}_{j t}-\phi \widetilde{\bar{M}}_{j t}}{\left[\gamma-\left(\frac{\eta \eta}{\eta-1}\right)\right]} \\
& \widetilde{\bar{E}}_{j t}=\frac{\zeta+\left(\frac{\eta}{\eta-1}\right)\left[\widetilde{P}_{E t}-\ln \gamma\right]-\alpha \widetilde{\bar{K}}_{j t}-\beta\left(\widetilde{\bar{L}}_{j t}+\widetilde{\bar{H}}_{j t}\right)-\phi \widetilde{\bar{M}}_{j t}}{\left[\phi-\left(\frac{\eta}{\eta-1}\right)\right]} \\
& \widetilde{\bar{M}}_{j t}=\frac{\zeta+\left(\frac{\eta}{\eta-1}\right)\left[\widetilde{P}_{M t}-\ln \phi\right]-\alpha \widetilde{\widetilde{K}}_{j t}-\beta\left(\widetilde{\bar{L}}_{j t}+\widetilde{\bar{H}}_{j t}\right)-\gamma \widetilde{\bar{E}}_{j t}}{[1} .
\end{aligned}
$$

Our baseline results use the above system of five equations to calculate the initial solution of the frictionless demands of all factors. Given the availability of plant-level prices, we can create measures of physical productivity and demand shocks. We use these measures to estimate the profitability shock $\widetilde{S}_{j t}$ directly from (the log of) equation (9). Estimates of the cost shocks and the technology and demand parameters are also necessary to estimate $\widetilde{S}_{j t}$, and these measures are generated as described in the text of the main paper. Using the fundamental parameters and shocks, estimated as described in the text of the main paper, and our estimate of $\widetilde{S}_{j t}$, we solve the above system numerically for each plant-year observation.

In the next step, we take advantage of the relationship between the solutions for the variable factors (materials, energy, and hours, not subject to adjustment costs) in the frictionless system above and the same variable factors in the "actual" profit maximization when capital and labor are subject to adjustment costs. The first order conditions for materials, energy and hours are just static first order conditions regardless, although the solution differs depending on whether capital and labor are frictionless as well or are subject to adjustment costs. Note further that in principle the solution for materials, energy and hours in the case where capital and labor are subject to adjustment costs should be equal to the observed values in the plant-level data and we exploit this in this second step.

With some manipulation of the first order conditions, the following identities emerge 
(where we denote the frictionless solution from the above system with an overline and the actual solution in the presence of adjustment costs with superscripts $a$ ):

$$
\frac{\bar{M}_{j t}}{\bar{\Lambda}_{j t}}=\frac{M_{j t}^{a}}{\Lambda_{j t}^{a}}, \quad \frac{\bar{E}_{j t}}{\bar{\Lambda}_{j t}}=\frac{E_{j t}^{a}}{\Lambda_{j t}^{a}}, \quad \text { and } \frac{\bar{H}_{j t}^{\delta}}{\bar{\Lambda}_{j t}}=\frac{\left(H_{j t}^{a}\right)^{\delta}}{\Lambda_{j t}^{a}}
$$

where we denote the plant-level revenue that would be implied by the revenue function evaluated at the levels of factors implied by the frictionless solution, as $\bar{\Lambda}_{j t}$ and the actual revenue values consistent with the presence of adjustment costs with a superscript $a$. These identities in turn imply a second set of identities $\frac{\bar{M}_{j t}}{M_{j t}^{a}}=\frac{\bar{E}_{j t}}{E_{j t}^{a}}$ and $\frac{\bar{M}_{j t}}{M_{j t}^{a}}=\left(\frac{\bar{H}_{j t}}{H_{j t}^{a}}\right)^{\delta}$, as implied by equation (16). Observe that these latter identities are such that the frictionless variable factors can be solved for recursively. Once we have one of the frictionless variable factors solved for we can solve for the others using the above equations.

We use these identities in this second stage of estimation as follows. We calculate $\bar{M}_{j t}$ from equation (16), where $\bar{\Lambda}_{j t}$ corresponds to the revenue function evaluated at the levels of factors obtained in the initial frictionless solution. We then compute a plant-specific constant proportional correction factor, and use it to obtain the measure of $\bar{M}_{j t}$ we use in the analysis. With $\bar{M}_{j t}$ and the second set of identities listed above, we recursively obtain $\bar{E}_{j t}$ and $\bar{H}_{j t}$.

Our plant-specific proportional correction factor for materials is chosen so that frictionless and actual materials are at the same level in at least one period (the period when materials is at its median growth). We use materials to generate the correction factor since, given the availability of plant-level prices for materials, materials is likely the most accurately measured of the variable factors, besides exhibiting a high cost share. In considering the need for such a correction factor, note that the frictionless revenue (and frictionless factors) estimates from the first stage will reflect any measurement error in the estimated parameters and shocks to technology, costs and demand. Since such measurement error may have a plant specific level effect (i.e., is not mean zero at the plant-level), the measurement error may imply that frictionless revenue estimated in the first step may be too high or too low in terms of levels relative to actual revenue (which reflects the adjustment costs for capital and labor). As such, our benchmarking of materials is intended to benchmark the ratio of actual to frictionless revenue at the plant level. Note that once we benchmark materials, the recursive nature of the solution for the other variable factors implies they will be benchmarked accordingly as well. We have explored alternatives to this procedure in terms of the number of periods we force the identity to hold for materials and the results are robust to alternatives. It is also important to note that the impact of the multiple 
steps including this correction factor is modest - for example, the correlation between the frictionless materials estimated in the first step and our final estimate of frictionless materials is 0.99. Recall further that the other frictionless factors (hours and energy) are estimated to satisfy the above identities once we have a measure of frictionless materials.

The remaining sections of this appendix reports robustness tests of alternative exercises, each of which changes part of the assumptions or the methodology used to obtain the baseline results.

\section{A.2. Sector level prices}

Our baseline results use plant-level prices as deflators for output, materials, and energy. Plant-level prices for materials and energy are also used in the calculation of frictionless factor demands, as they appear in the first-order conditions of the profit maximization problem. To investigate the potential gains of having access to plant-level prices, we reestimate adjustment functions using sector-level prices for output, energy, and materials. Note that in the absence of plant-level prices we are unable to adequately separate physical productivity from demand shocks, so in the system of five first-order conditions reported above we rather use a composite profitability shock, $\widetilde{S}_{j t}$. We estimate this shock as a residual from the revenue function (10), where factor elasticities are the aggregate cost shares, and where the elasticity of demand is set exogenously to -2 . This demand elasticity is close to our estimate for the baseline case (see also Eslava et al., 2004).

Results using sector-level prices are reported in Figures 1.a and 2.a. Comparing these figures with the baseline results in the paper, which use plant-level prices, suggests that using sector-level prices introduces substantial measurement error. In Figure 2.a, the adjustment hazard is negative for a wide range of relevant capital surpluses relatively close to zero. A negative adjustment hazard is an indication of mismeasurement of surpluses as this would imply that a plant that wishes to reduce its capital stock actually increases it. Other aspects of the adjustment hazards also look anomalous. We find that for both labor and capital shortages that the post-reform hazards are lower than the pre-reform hazards. While the impact of the reform is an empirical question, a finding going in the opposite direction from predicted effects and also in the opposite direction from what we find for the baseline results is another indication of measurement error. In this case, the lack of plant-level data would yield quite misleading inferences about the impact of the reforms on adjustment. 


\section{A.3. Alternative Measures of Frictionless/Desired Plant-level Constants}

Desired and frictionless factor demands are assumed to relate to each other as follows:

$$
\begin{aligned}
L_{j t}^{*} & =\bar{L}_{j t} \theta_{L j}, \\
K_{j t}^{*} & =\bar{K}_{j t} \theta_{K j},
\end{aligned}
$$

where $\bar{L}_{j t}$ and $\bar{K}_{j t}$ are the frictionless demands of employment and capital, $L_{j t}^{*}$ and $K_{j t}^{*}$ are the corresponding desired demands, and $\theta_{L j}$ and $\theta_{K j}$ are plant-specific employment and capital constants. In the baseline estimation reported in Eslava et al. (2008) these constants are calculated as ratios between the actual and the frictionless employment and capital levels for the year in which the plant is at its median employment growth and investment, respectively. To explore the robustness of our results to this choice of plantspecific constants, we produce results using an alternative definition of $\theta_{L j}$ and $\theta_{K j}$. In particular, we calculate these constants as ratios between the actual and the frictionless employment and capital levels for the three years in which the plant is closest to its median employment growth and investment, when the plant is in the sample for more than ten years. For plants that are in the sample for ten years or less, we use the same definition of these constants used for the baseline estimation. Results of this alternative exercise are reported in Figures 1.b and 2.b. No important differences arise with respect to the baseline case. We chose to keep the baseline case rather than this alternative, since it treats long-lived and short-lived plants symmetrically.

\section{A.4. Alternative Estimates of Factor Elasticities}

The baseline results estimate factor elasticities as aggregate (at the manufacturing sector) cost shares. We have also re-estimated our results using sector-level cost shares. Note that this change may, in principle, affect the factor elasticities themselves, the resulting measure of TFP, and the demand estimation, as TFP is used as an instrument in this estimation. In practice, we obtain virtually identical results, as reported in Figures 1.c and 2.c. We chose to use the aggregate elasticities since this permitted us to compare this case to other alternatives. For example, we have also produced another set of results using the IV-based factor elasticities proposed in Eslava et al. (2004). ${ }^{32}$ Results are reported in

\footnotetext{
${ }^{32}$ These IV-based elasticities can only be estimated at the aggregate level, given the limited variability of some of the instruments. Our baseline case uses aggregate cost shares precisely to be able to compare to results obtained using the IV-based elasticities.
} 
Figure 1.d and 2.d. The basic patterns of the effects of reforms also hold when we allow elasticities to vary by sector, although some differences with our baseline results can be observed. Adjustment functions are generally flatter in this version, and the hazard of adjustment for capital turns out negative in part of the relevant range of capital surpluses. As mentioned above, this negative hazard suggests greater measurement error with this set of factor elasticities, compared to our baseline estimation.

\section{A.5. Alternative Measures of User Cost of Capital}

The baseline estimation of frictionless factor demands imposes an exogenous value for the user cost of capital of $R_{t}=0.15$, based on previous estimates for Colombia. However, a frictionless environment may imply a lower user cost of capital. We reproduced our results using $R_{t}=0.08$ with almost identical results, as reported in Figures 1.e and 2.e.

One could also think that reforms affected factor adjustment through an effect in the user cost of capital. To explore this possibility, we set the user cost of capital equal to the (ex-post) real interest rate (Figures 1.f and 2.f.). The shapes of the adjustment functions and the effects of the reforms are similar to those obtained for the baseline case, suggesting our baseline estimation is not missing the effects of reforms by assuming a constant user cost of capital. However, there is evidence of greater measurement error when we use the real interest rate: part of the adjustment functions display negative adjustment hazards and decreasing shapes. This is probably not surprising given the well-known problems of the ex-post interest rates to approximate the user cost of capital. Since, to our knowledge, there is no reliable estimation of the ex ante user cost of capital for Colombia for our period of study (at least not one that varies over time), we prefer keeping a constant value of $R_{t}$ as our baseline assumption. Note that Caballero, Engel and Haltiwanger (1995) also use a constant value of the interest rate for similar reasons for the U.S.

\section{A.6. Alternative Parameterization of Wage Function}

Our baseline case assumes $\delta=2$, based on estimates for the US. We examine the robustness of our results to changes in the value of $\delta$. Figures 1.g and 2.g. show the results when we assume $\delta=3$. Results do not show important changes.

\section{A.7. Balanced Panel}

Our baseline results are estimated including all plants present in $t-1, t$, and $t+1$ (pairwise continuers). We re-estimate those results restricting our sample to the balanced 
panel. Results are reported in Figures 1.h and 2.h. These results are similar to those obtained for the whole sample of pairwise continuers, except that plants in the balanced sample display more pronounced non-linearities. 


\section{References}

[1] Banerjee, Abhijit and Esther Duflo. 2005. "Growth Theory through the Lens of Economic Development." Handbook of Development Economics, Vol. 1a. Amsterdam: Elsevier, 473-552.

[2] Bartelsman, Eric, John Haltiwanger and Stefano Scarpetta. 2006. "Cross Country Differences in Productivity: The Role of Allocative Efficiency," Mimeo.

[3] Bertola, Giuseppe and Ricardo Caballero. 1994. "Irreversibility and Aggregate Investment", Review of Economic Studies, 61(2): 223-246.

[4] Bils, Mark. 1987. "The Cyclical Behavior of Marginal Cost and Price," American Economic Review, 77(5): 838-856.

[5] Bloom, Nicholas. 2007. "The Impact of Uncertainty Shocks," NBER Working Paper No. 13385.

[6] Caballero, Ricardo and Eduardo Engel. 1993. "Microeconomic Adjustment Hazards and Aggregate Dynamics," Quarterly Journal of Economics 433(2): 359-383.

[7] Caballero, Ricardo and Eduardo Engel. 1999. "Explaining Investment Dynamics in U.S. Manufacturing: A Generalized(S,s) Approach," Econometrica 67(4): 783-826.

[8] Caballero, Ricardo, Eduardo Engel and John Haltiwanger. 1995. "Plant-level Adjustment and Aggregate Investment Dynamics," Brookings Papers on Economic Activity 2: $1-54$.

[9] Caballero, Ricardo, Eduardo Engel and John Haltiwanger. 1997. "Aggregate Employment Dynamics: Building from Microeconomic Evidence," American Economic Review, 87: 115-137.

[10] Caballero, Ricardo, Eduardo Engel and Alejandro Micco. 2004. "Effective Labor Regulation and Microeconomic Flexibility," Cowles Foundation Working Paper No. 1480.

[11] Cooper, Russell and John Haltiwanger. 2006. "On the Nature of Capital Adjustment Costs," Review of Economic Studies, 73(3): 611-633.

[12] Cooper, Russell, John Haltiwanger and Laura Power. 1999. "Machine Replacement and the Business Cycle: Lumps and Bumps," American Economic Review, 89: 921946. 
[13] Cooper, Russell and Jonathan Willis. 2003. "The Economics of Labor Adjustment: Mind the Gap," Federal Reserve Bank of Kansas City 03-05, July 2003.

[14] Doms, Mark and Tim Dunne. 1998. "Capital Adjustment Patterns in U.S. Manufacturing Plants." Review of Economic Dynamics, 1: 409-429.

[15] Edwards, Sebastian. 2001. The Economic and Political Transition to an Open Market Economy: Colombia. Paris: OECD.

[16] Eslava, Marcela, John Haltiwanger, Adriana Kugler and Maurice Kugler. 2004. "The Effects of Structural Reforms on Productivity and Profitability Enhancing Reallocation: Evidence from Colombia," Journal of Development Economics, 75(2): 333-371.

[17] Eslava, Marcela, John Haltiwanger, Adriana Kugler and Maurice Kugler. 2006. "Plant Turnover and Structural Reforms in Colombia," IMF Staff Papers, 53: 58-75.

[18] Fernandes, Ana. 2007. "Trade Policy, Trade Volumes and Plant-level Productivity in Colombian Manufacturing Industries," Journal of International Economics 71(1): $52-71$.

[19] Foster, Lucia, John Haltiwanger and Chad Syverson. 2008. "Reallocation, Firm Turnover and Efficiency: Selection on Productivity or Profitability," American Economic Review (forthcoming).

[20] Gelos, R. Gaston and Alberto Isgut. 2001. "Fixed Capital Adjustment: Is Latin America Different?," Review of Economics and Statistics, 83(4): 717-730.

[21] Gourio, F. and A. Kashyap. 2007. "Investment Spikes: New Facts and a General Equilibrium Explanation," Journal of Monetary Economics, forthcoming.

[22] Hall, Robert E. 2004. "Measuring Factor Adjustment Costs," Quarterly Journal of Economics, 119(3): 899-927.

[23] Hsieh, Chang-Tai and Peter Klenow. 2006. "Misallocation and Manufacturing Productivity in China and India," Mimeo.

[24] Hopenhayn, Hugo and Richard Rogerson. 1993. "Job Turnover and Policy Evaluation: A General Equilibrium Analysis," Journal of Political Economy, 101(5): 915-938. 
[25] Kugler, Adriana and Maurice Kugler. 2009. "Labor Market Effects of Payroll Taxes in Developing Countries: Evidence from Colombia," forthcoming in Economic Development and Cultural Change.

[26] Kugler, Adriana. 2005. "Wage-Shifting Effects of Severance Payments Savings Accounts in Colombia," Journal of Public Economics, 89(2-3): 487-500.

[27] Kugler, Adriana. 1999. "The Impact of Firing Costs on Turnover and Unemployment: Evidence from the Colombian Labor Market Reform," International Tax and Public Finance Journal, 6(3): 389-410.

[28] Kugler, Maurice. 2006. "Spillovers from Foreign Direct Investment: Within or Between Industries?," Journal of Development Economics, 80(2): 444-477.

[29] Lora, Eduardo. 2001. "Structural Reforms in Latin America: What Has Been Reformed and How to Measure It," Inter-American Development Bank Working Paper No. 466.

[30] Nadiri, Ishak and Sherwin Rosen. 1969. "Interrelated Factor Demand Functions," American Economic Review, 59: 457-71.

[31] Nilsen, Oivind and Fabio Schiantarelli. 2003. "Zeroes and Lumps in Investment: Empirical Evidence on Irreversibilities and Nonconvexities" Review of Economics and Statistics, 85(4): 1021-1043.

[32] Polder, Michael, Gerard Pfann and Wilko Letterie. 2004. "Non-linear Investment Dynamics and Labor Adjustment," Working paper, Department of Quantitative Economics, Maastricht University).

[33] Olley and Pakes. 1996. "The Dynamics of Productivity in the Telecommunications Equipment Industry," Econometrica, 64: 1263-1297.

[34] Restuccia, Diego and Richard Rogerson. 2007. "Policy Distortions and Aggregate Productivity with Heterogeneous Plants," NBER Working Paper No. 13018.

[35] Rossana, Robert. 1990. "Interrelated Demands for Buffer Stocks and Productive Inputs: Estimates for Two-digit Manufacturing Industries," Review of Economics and Statistics, 72: 19-29.

[36] Shapiro, Matthew. 1986. "The Dynamic Demand for Capital and Labor," Quarterly Journal of Economics, 101: 513-42. 
Figure 1: Estimated Employment Adjustment Function and Distribution of Employment Shortages, Pre- and Post-Reform $(x=0)$

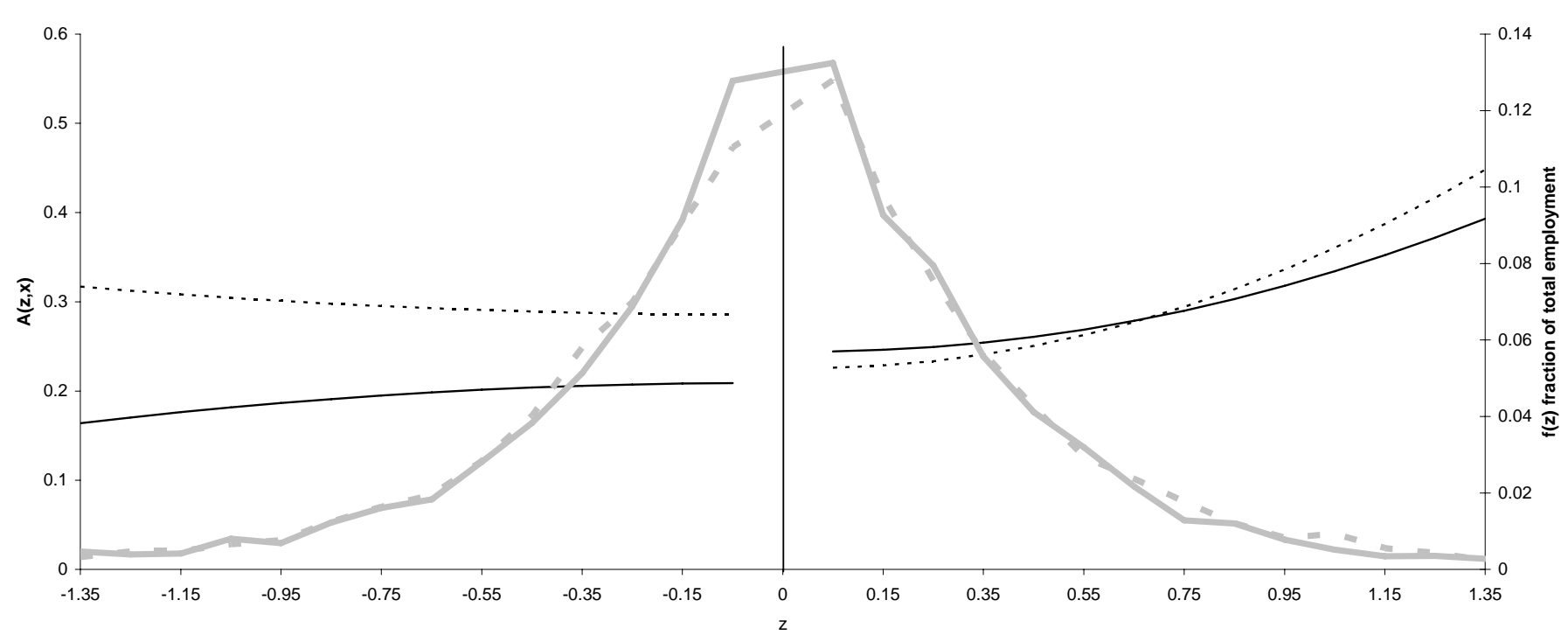

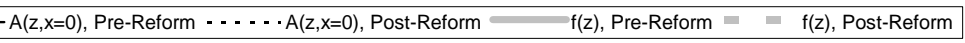

Figure 2: Estimated Capital Adjustment Function and Distribution of Capital Shortages,

Pre- and Post-Reform $(z=0)$

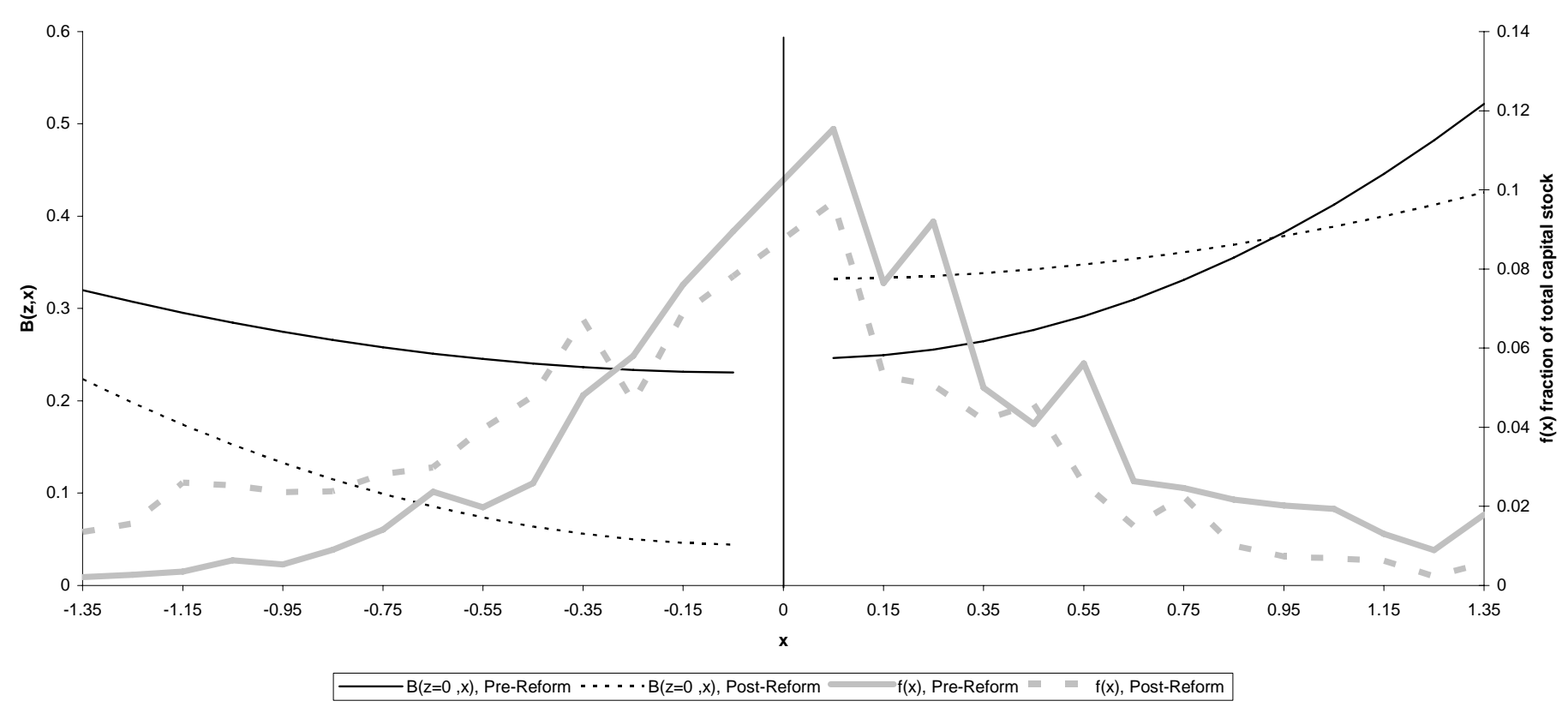


Figure 1.b: Estimated Employment Adjustment Function: Alternative Definition of Theta

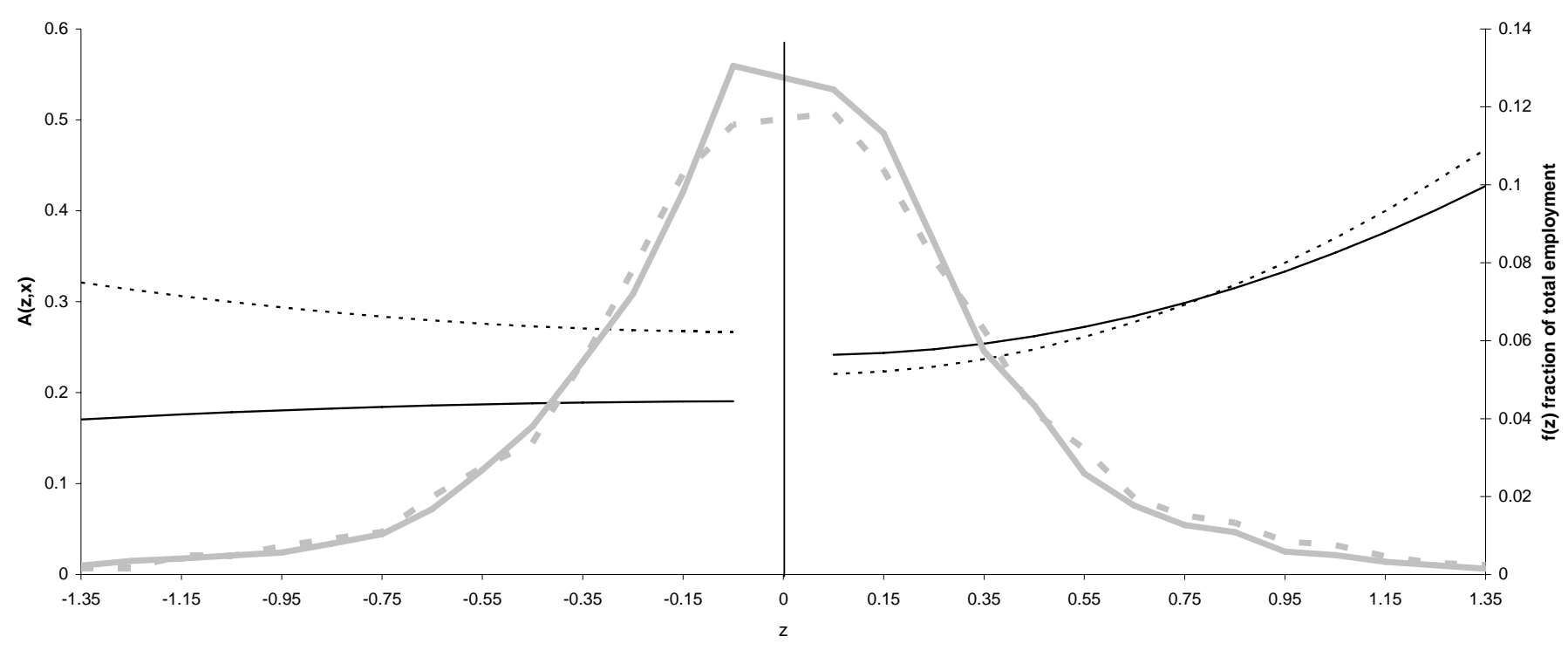

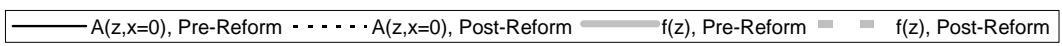

Figure 2.b: Estimated Capital Adjustment Function: Alternative Definition of Theta

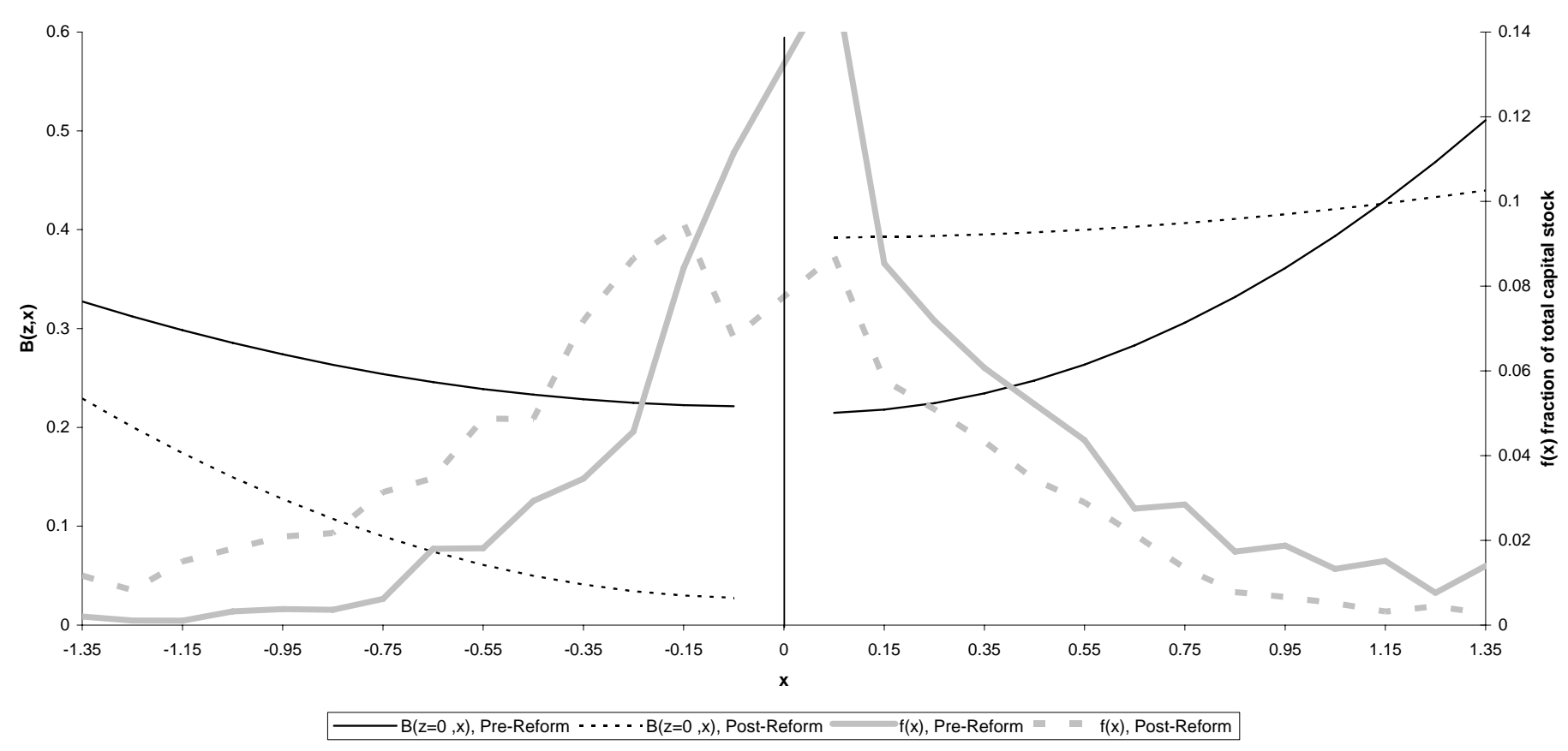


Figure 1.c: Estimated Employment Adjustment Function: Sector Level Cost Shares

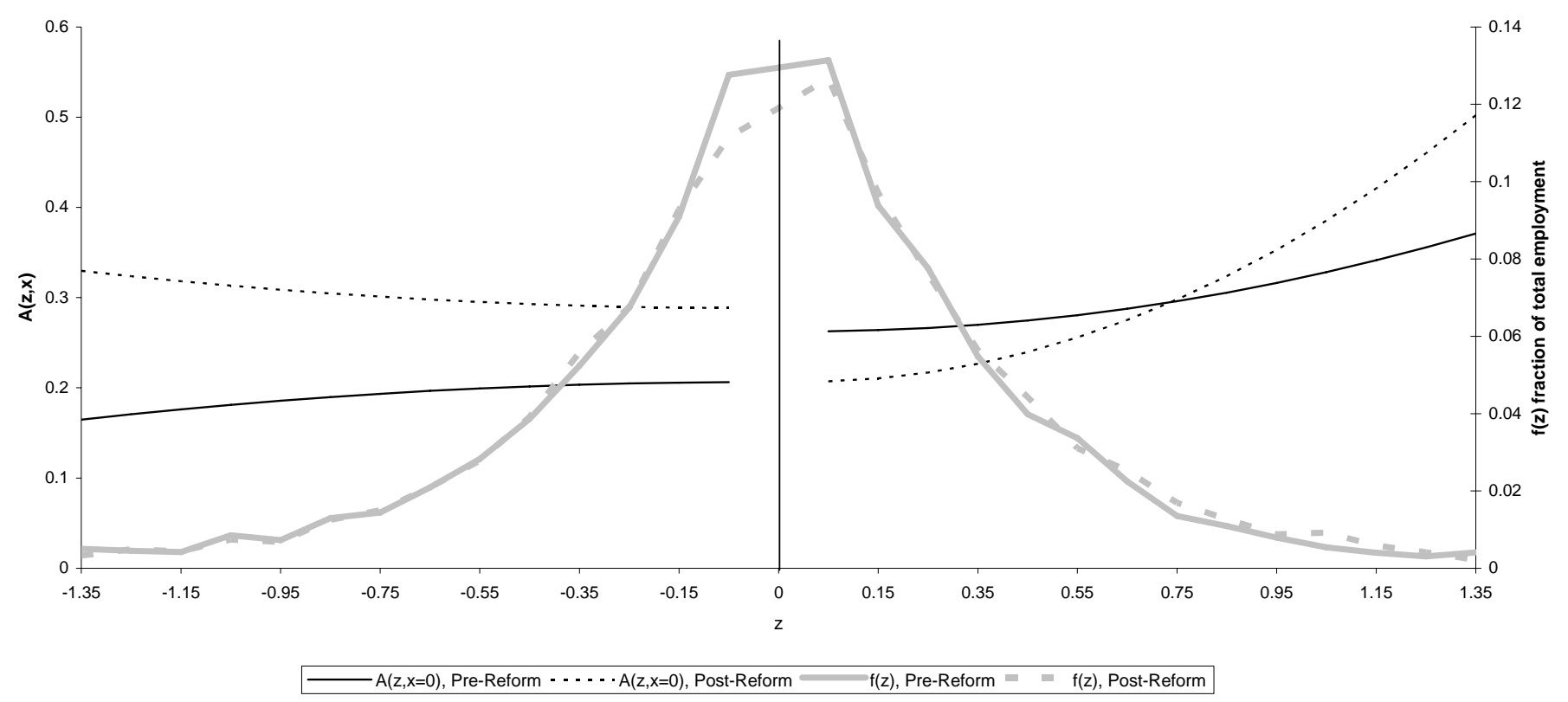

Figure 2.c: Estimated Capital Adjustment Function: Sector Level Cost Shares

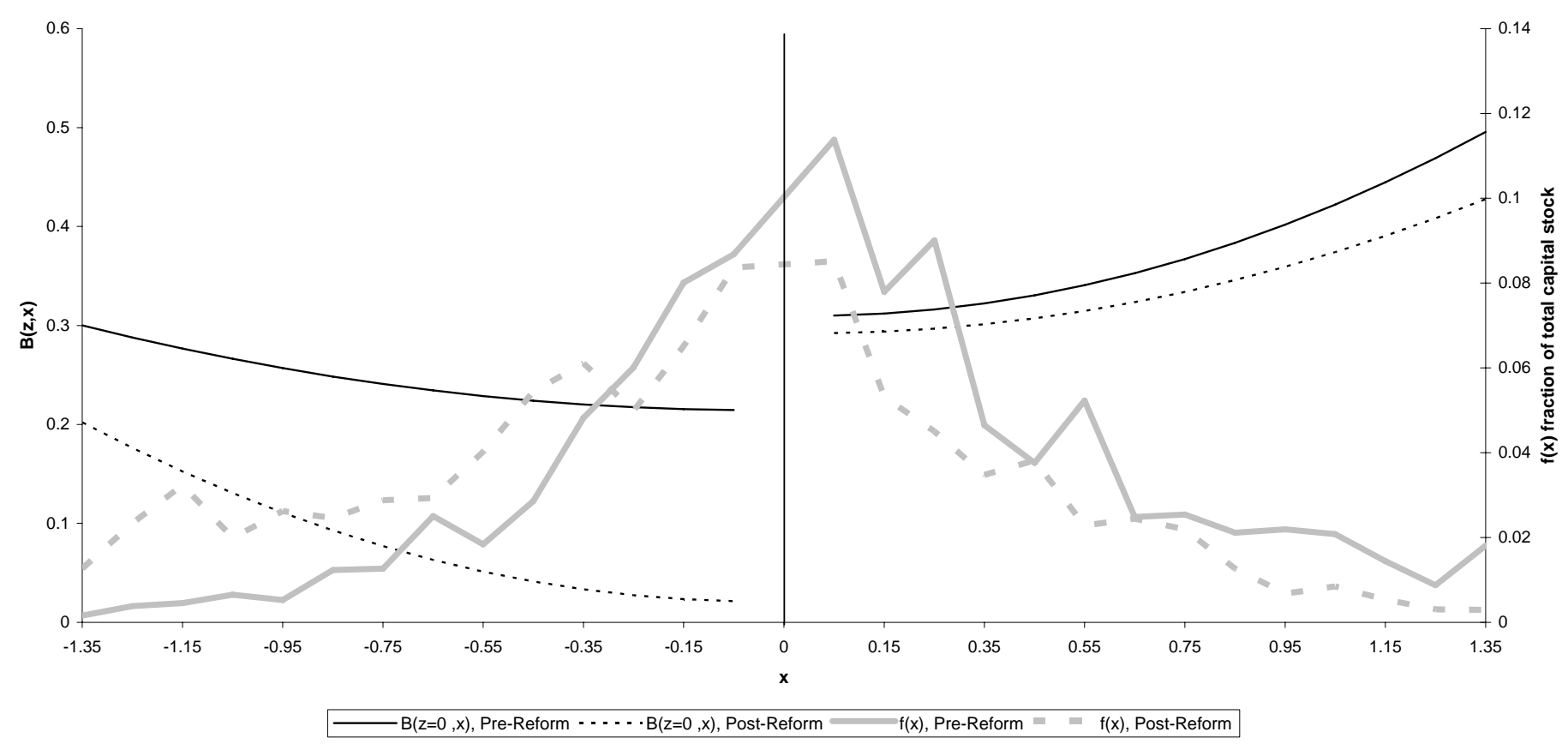


Figure 1.d: Estimated Employment Adjustment Function: IV Factor Elasticities

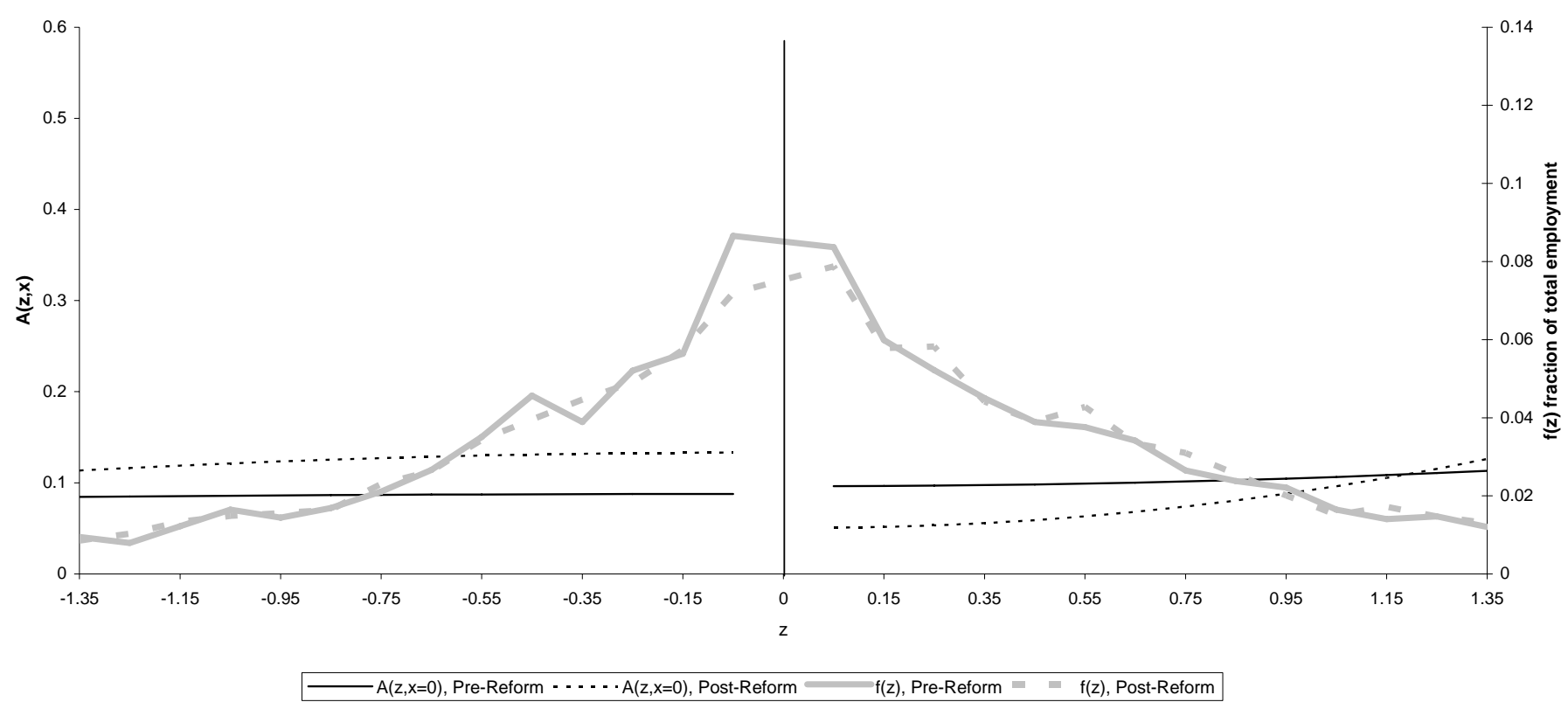

Figure 2.d: Estimated Capital Adjustment Function: IV Factor Elasticities

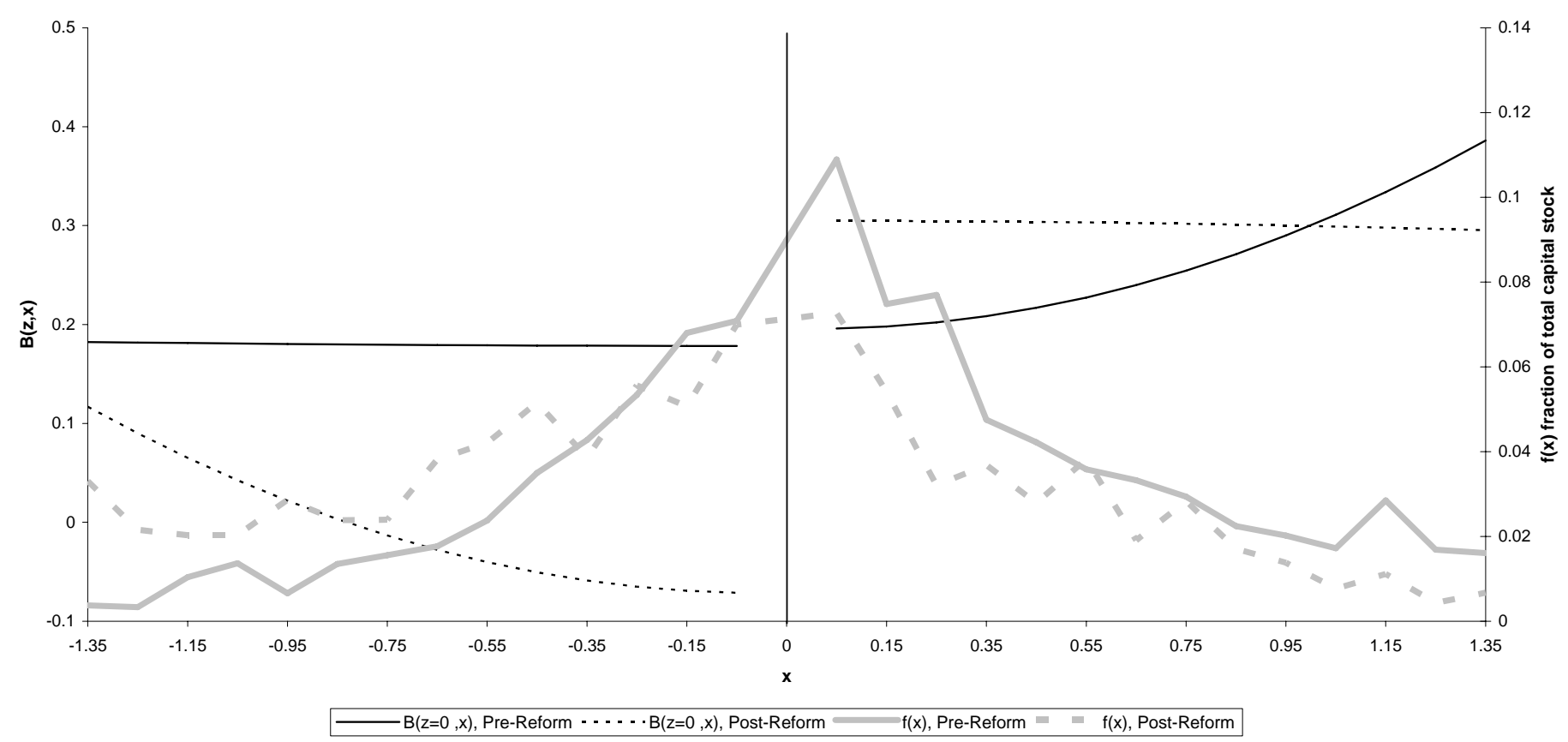




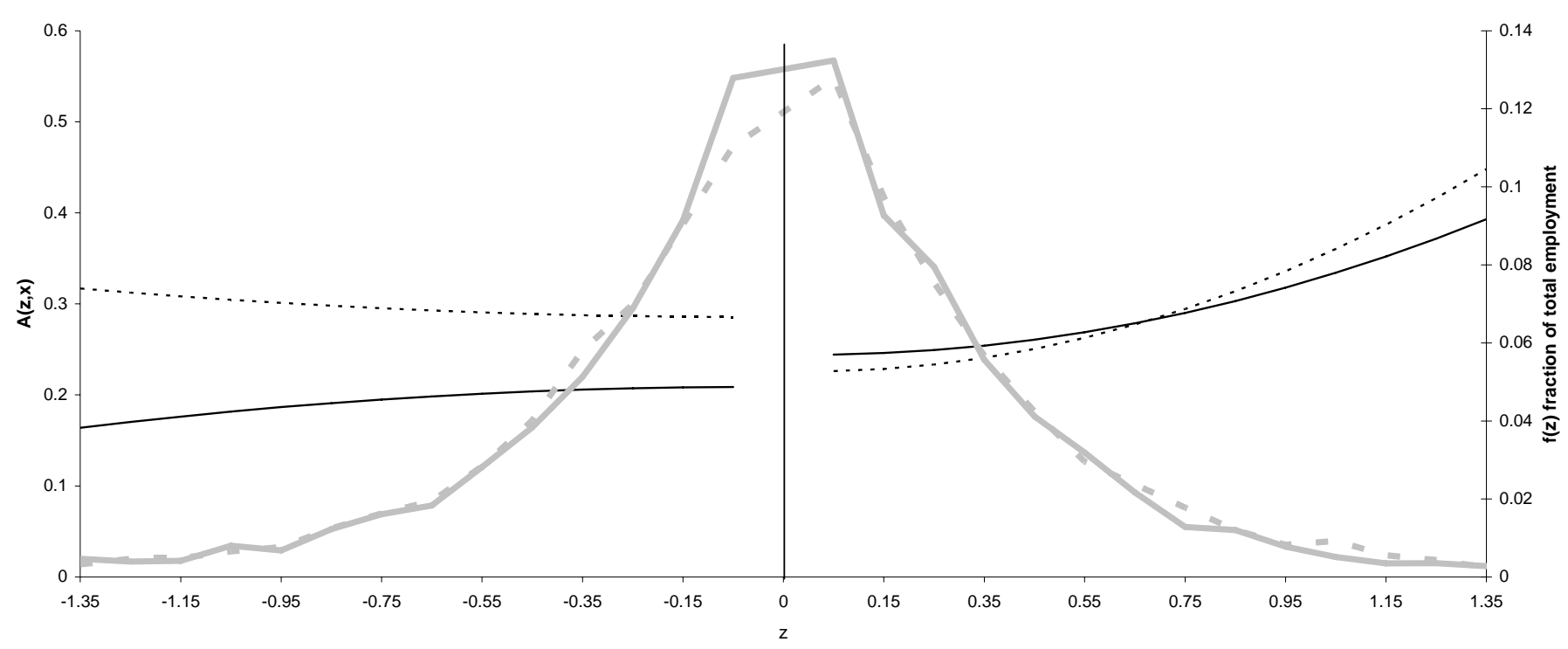

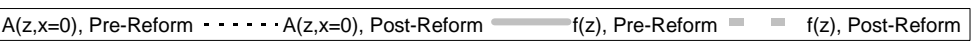

Figure 2.e: Estimated Capital Adjustment Function: User Cost of Capital $=\mathbf{0 . 0 8}$

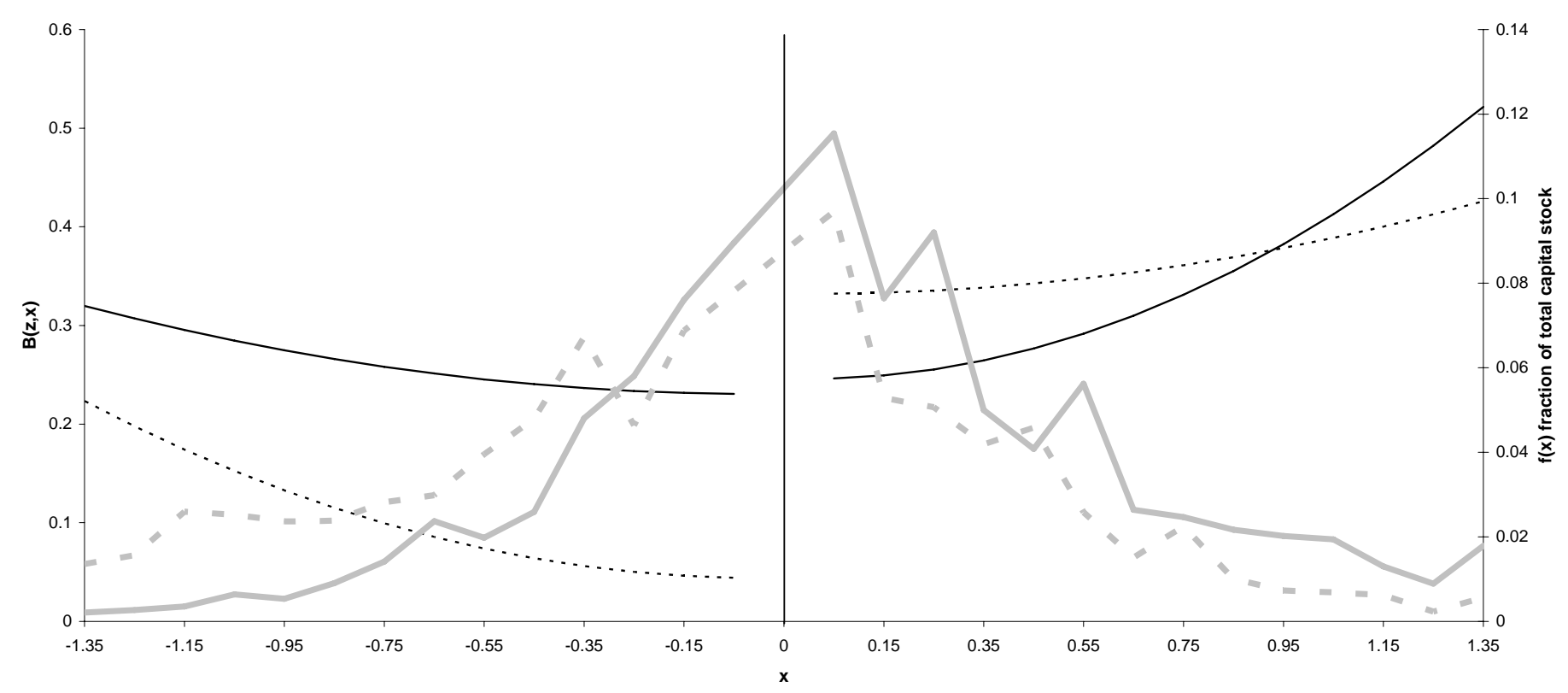

- $\mathrm{B}(\mathrm{z}=0, \mathrm{x})$, Pre-Reform $\cdots \cdots \cdot \mathrm{B}(\mathrm{z}=0, \mathrm{x})$, Post-Reform $\mathrm{f}(\mathrm{x})$, Pre-Reform $=\mathrm{f}(\mathrm{x})$, Post-Reform 


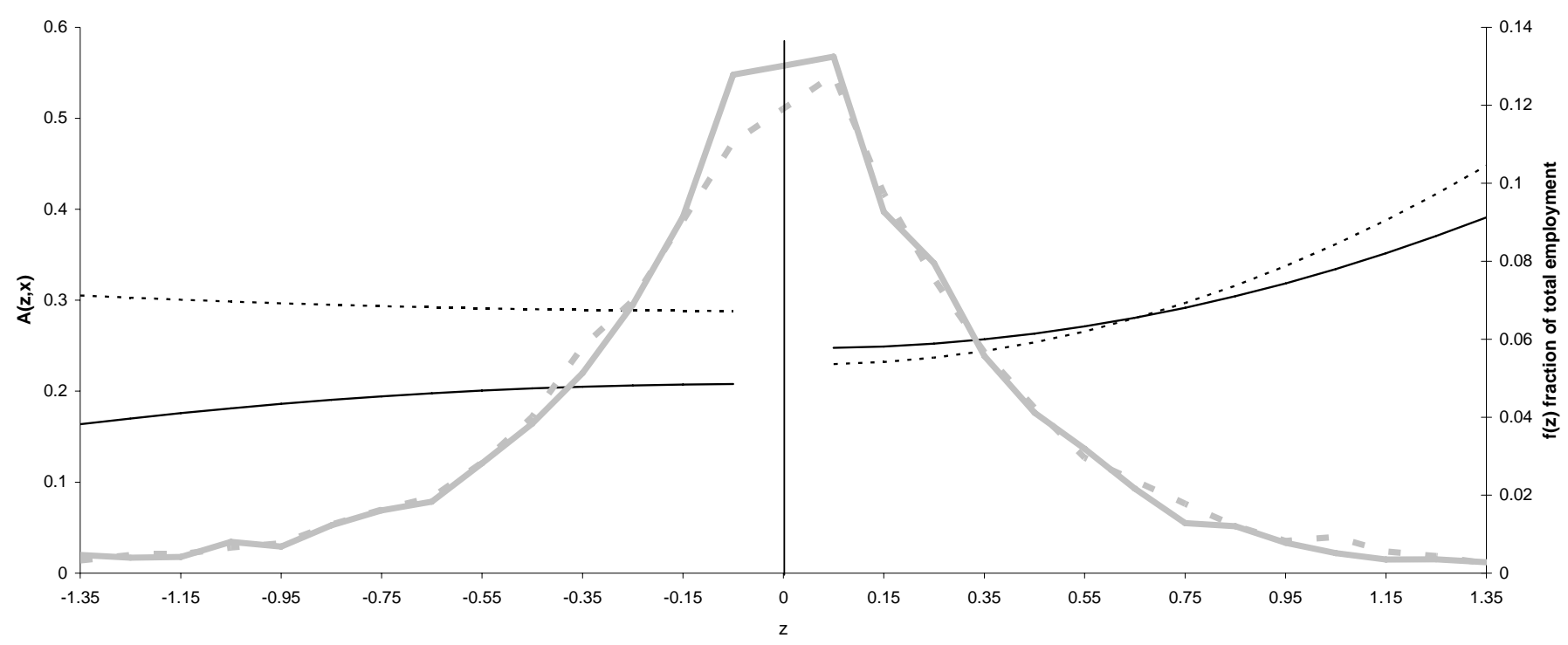

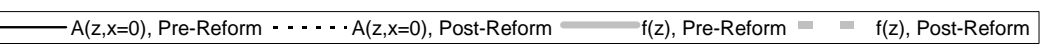

Figure 2.f: Estimated Capital Adjustment Function: Real Interest Rate

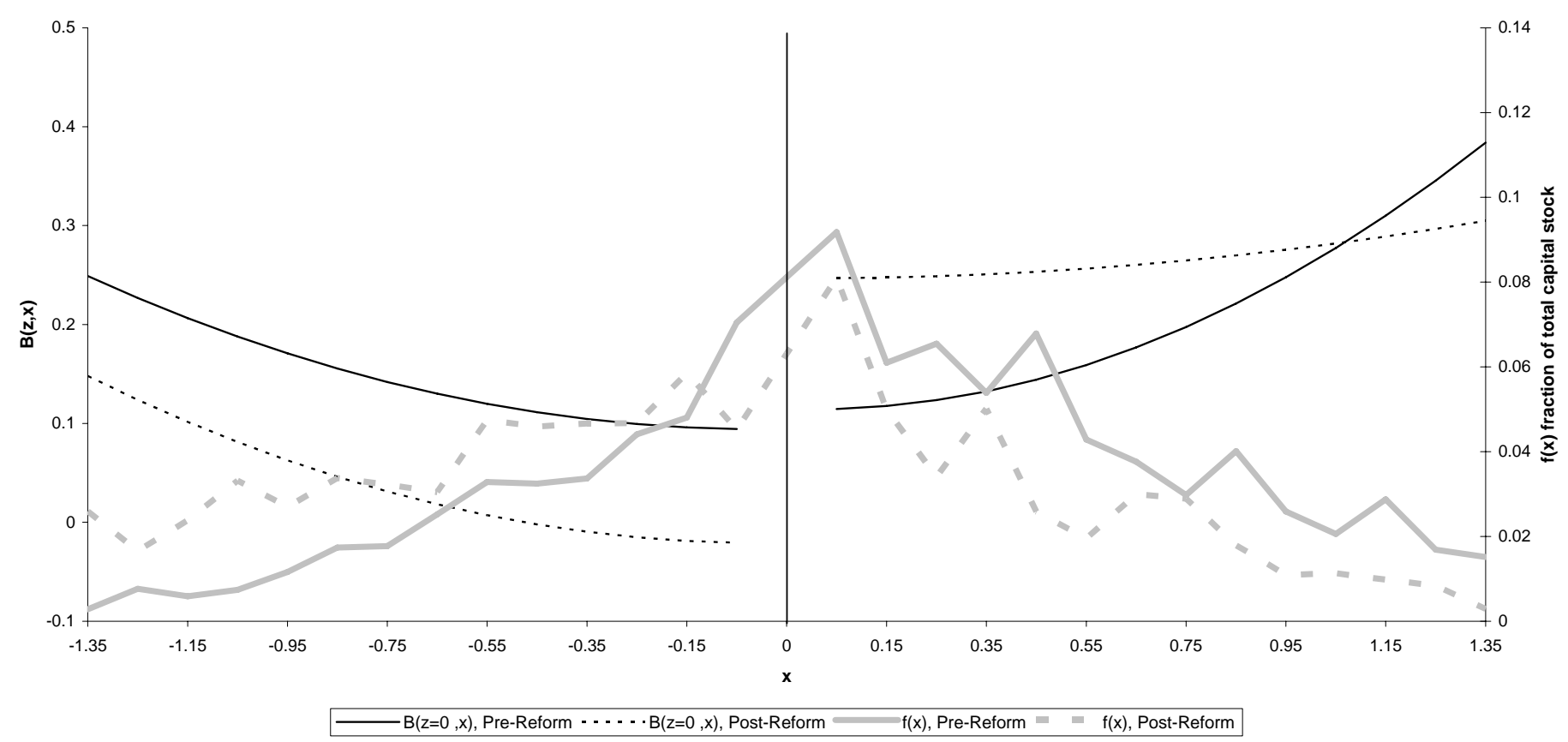




\section{Figure 1.g: Estimated Employment Adjustment Function: Delta=3}

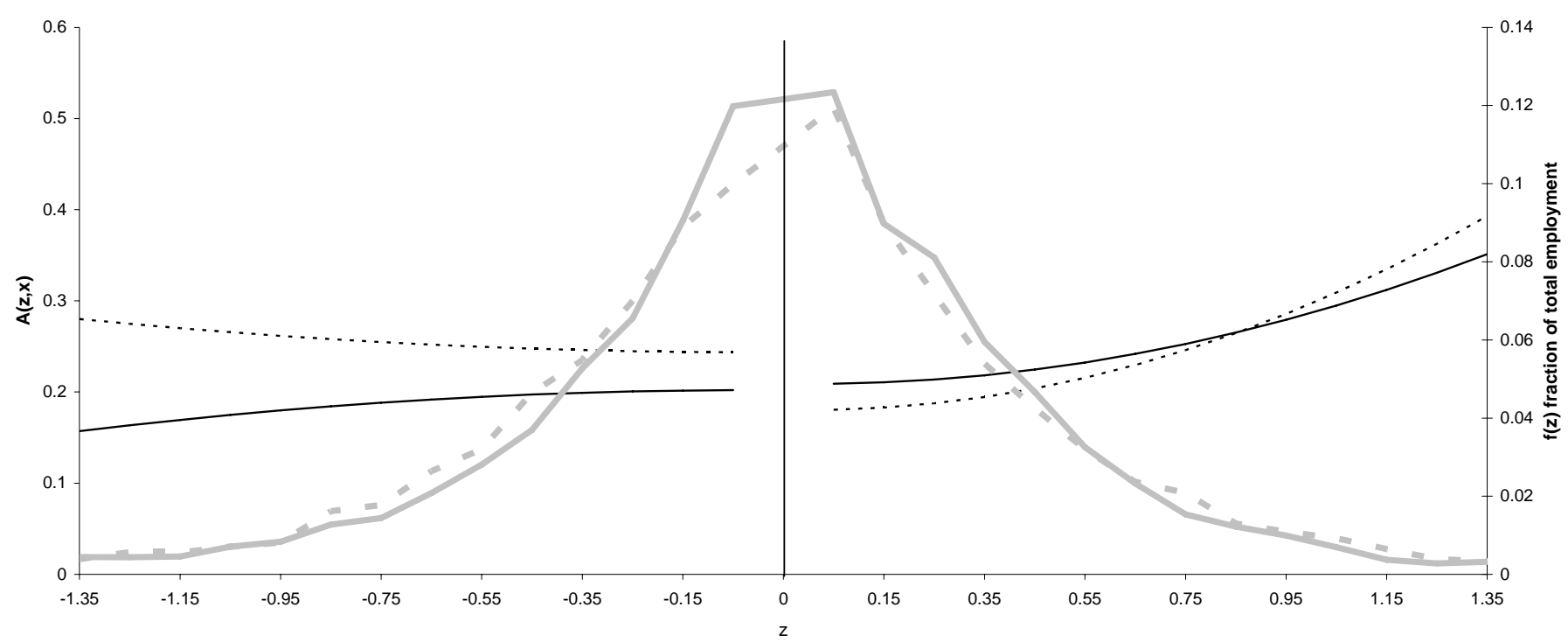

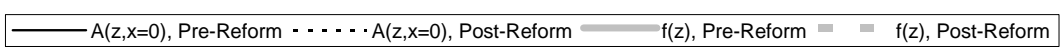

Figure 2.g: Estimated Capital Adjustment Function: Delta=3

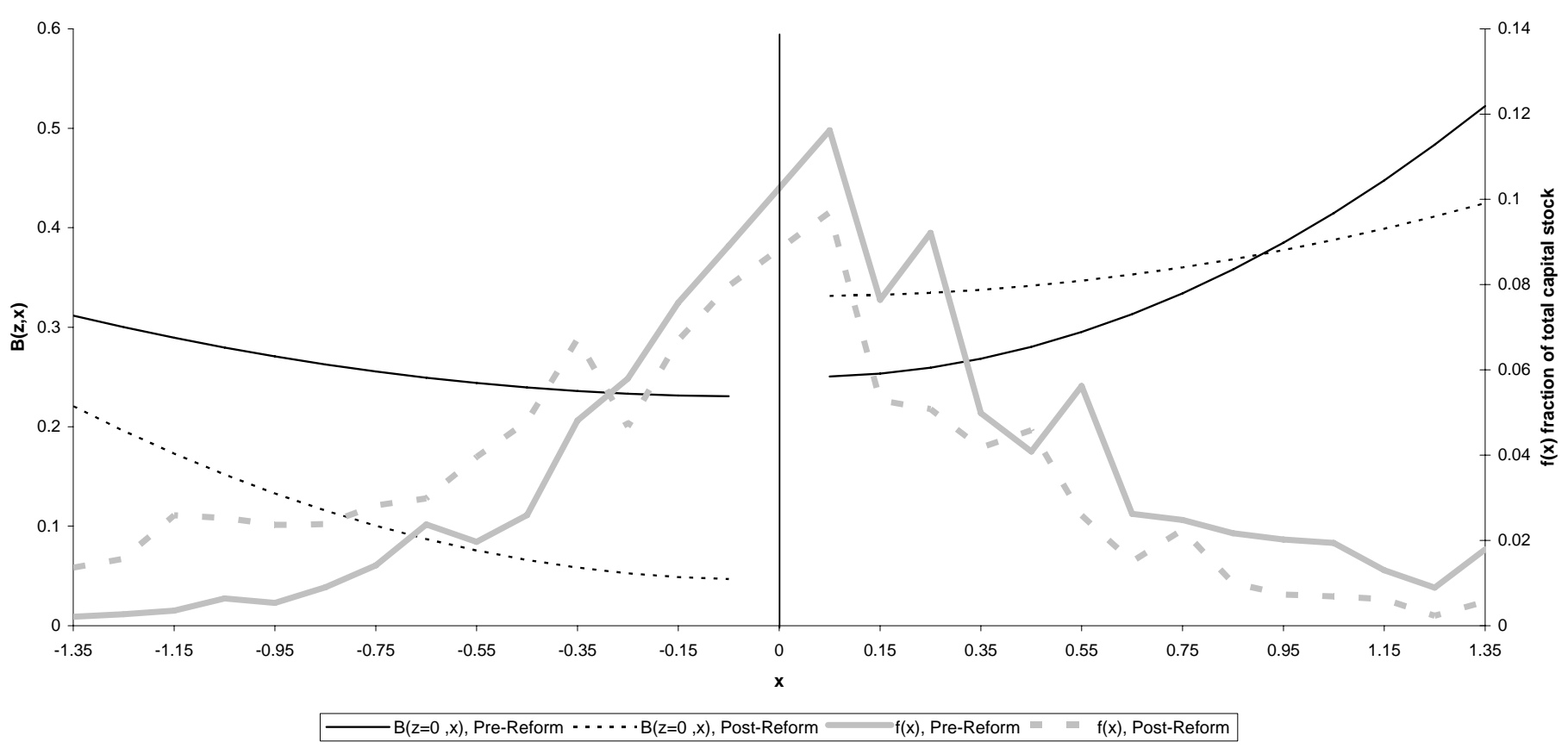




\section{Figure 1.h: Estimated Employment Adjustment Function: Balanced Panel}

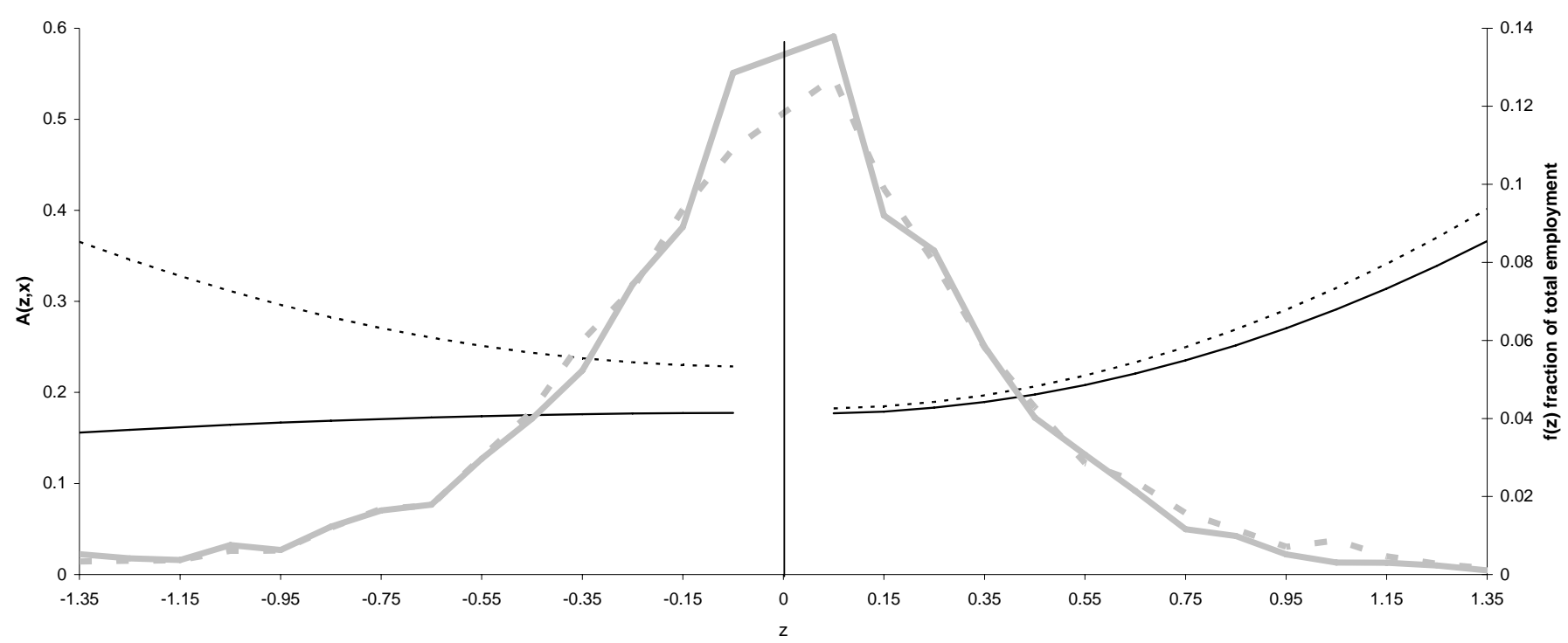

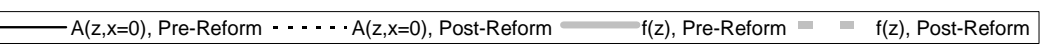

Figure 2.h: Estimated Capital Adjustment Function: Balanced Panel

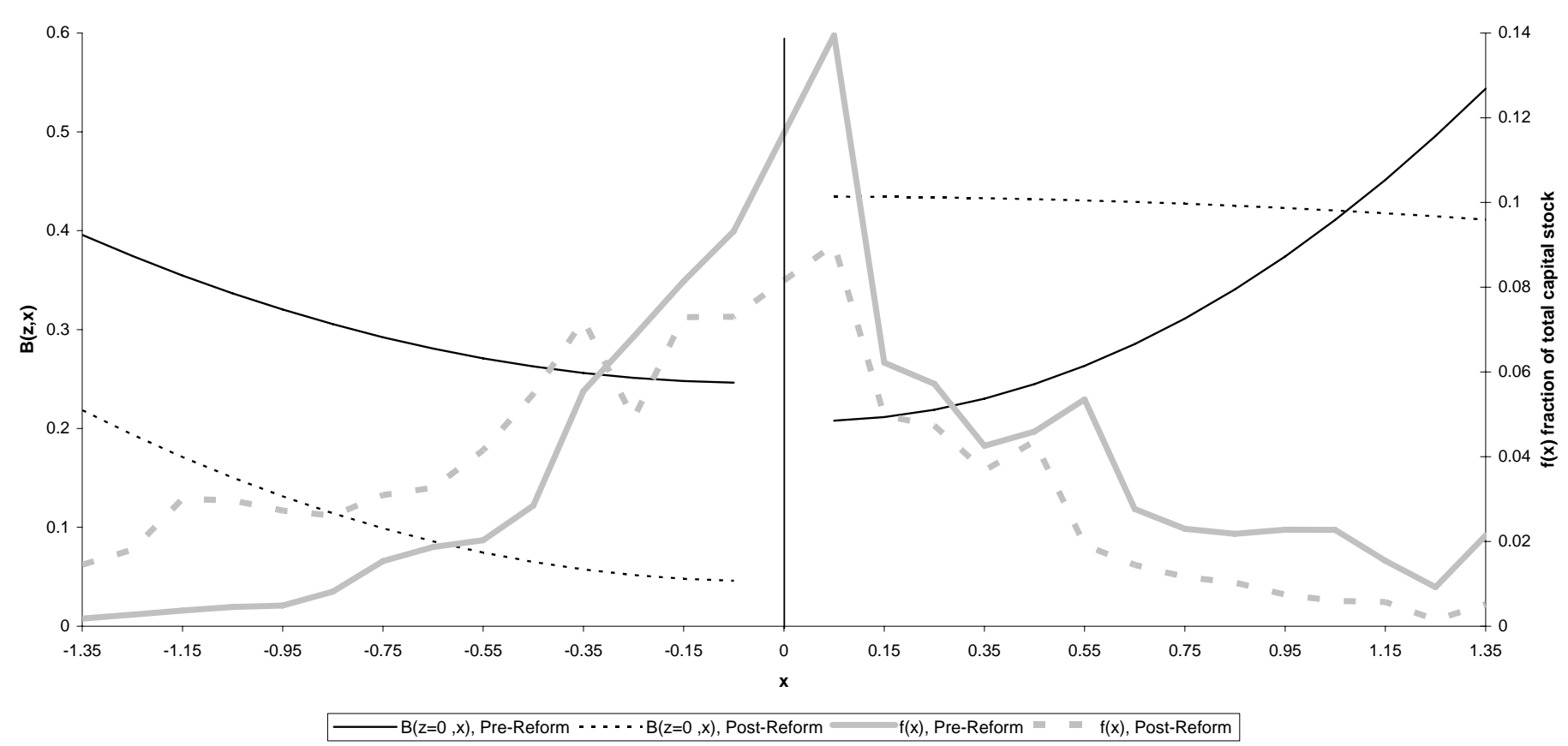




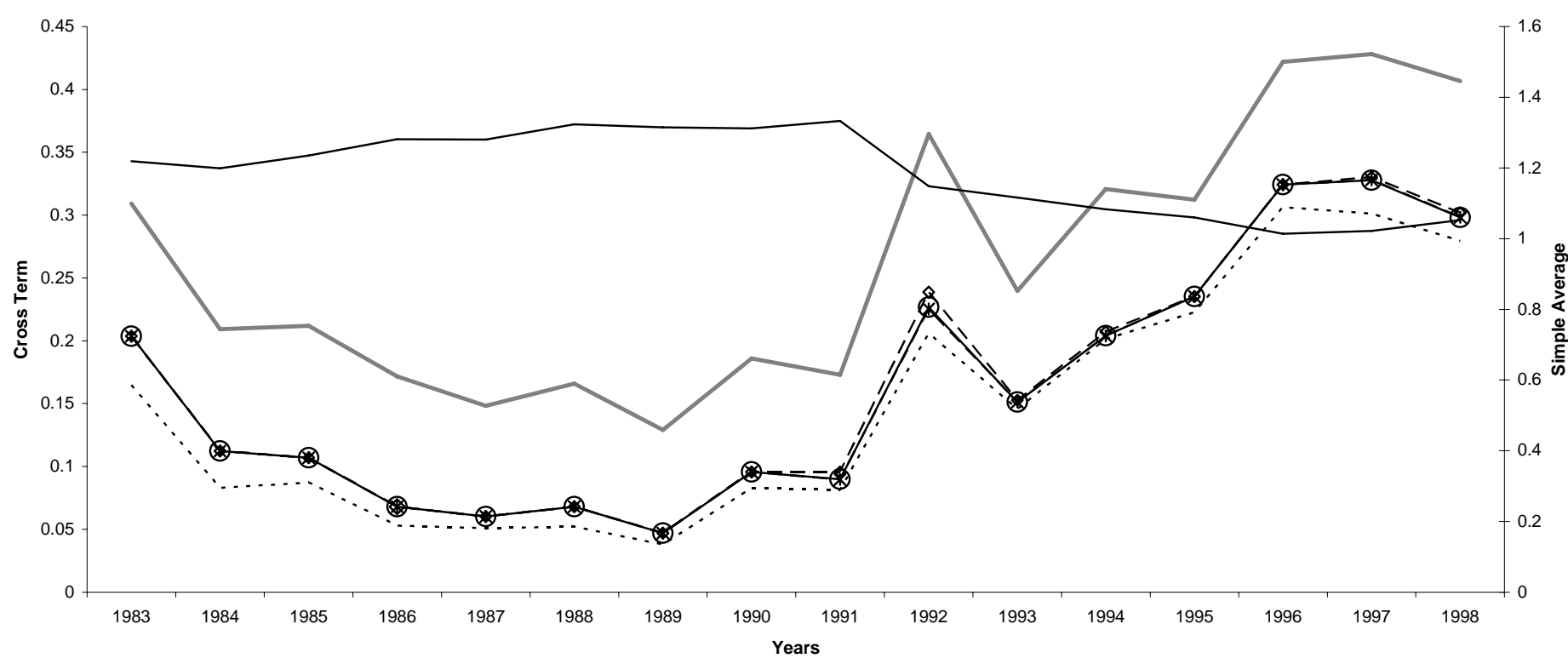

Table 1: Output Weighted Descriptive Statistics, Before and After Reforms

\begin{tabular}{lccc}
\hline \hline Variable & Pre-Reforms & Post-Reforms \\
\cline { 1 - 2 } Output & 14.13 & 14.96 \\
Employment & $(1.73)$ & $(1.80)$ \\
Capital & 5.51 & 5.56 \\
& $(1.27)$ & $(1.24)$ \\
Energy Consumption & 11.80 & 12.48 \\
& $(2.09)$ & $(2.05)$ \\
Materials Use & 14.79 & 14.94 \\
& $(2.16)$ & $(2.02)$ \\
Output Prices & 13.22 & 13.72 \\
& $(1.84)$ & $(1.76)$ \\
Material Prices & -0.17 & -0.68 \\
& $(0.46)$ & $(0.96)$ \\
Energy Prices & 0.04 & -0.14 \\
& $(0.34)$ & $(0.48)$ \\
Wages & 0.18 & 0.33 \\
& $(0.84)$ & $(0.80)$ \\
TFP & 5.24 & 5.38 \\
& $(0.26)$ & $(0.31)$ \\
Demand Shocks & 1.41 & 1.72 \\
& $(0.66)$ & $(1.12)$ \\
Labor Shortage & 13.20 & 13.47 \\
& $(1.63)$ & $(1.57)$ \\
Capital Shortage & 0.11 & 0.12 \\
& $(0.55)$ & $(0.53)$ \\
N & 0.31 & -0.05 \\
& $(0.61)$ & $(0.64)$ \\
\hline \hline
\end{tabular}

Notes: This table reports means and standard deviations of the log of quantities and of prices deviated from yearly producer price indices, as well as means and deviations of yearly wages in thousands of pesos of 1982. It also reports the first two moments of labor and capital shortages estimated using equations (1) and (2). All statistics are weighted by output. The pre-reform period includes the years 1982-1990, while the post-reform period includes the years 1991-1998. The sample has been restricted to observations for which both labor and capital shortages could be calculated. 
Table 2: Labor Adjustment Functions (c.1-c.6) and Capital Adjustment Functions (c.7-c.12) Weighted by Employment and Capital, Respectively

(1)

PAM

(2)

(3)

(4)

PAM/

NLAM

NLAM /

NLAM/

(6)

POSREF

CROSS

NLAM/

(7)

TERMS

CROSS

PAM

(8)

(9)

(10)

NLAM /

(11)

PAM/

NLAM

POSREF

NLAM/

NLAM

TERMS

TERMS

CROSS

TERMS

Constant

0.2725

0.2373

0.2439

0.2084

0.2512

0.2089

0.3045

0.3876

(0.0079)

(0.0024)

(0.0037)

0.1999

0.0719

0.2306

$\begin{array}{llll}-0.0068 & 0.0483 & -0.0140 & 0.0353\end{array}$

Pos. Shortage

$(0.0100)$

(0.0118)

$(0.0102)$

$(0.0122)$

$\begin{array}{llll}-0.0248 & -0.0264 & -0.0143 & -0.0246\end{array}$

0.2439

$-0.0248$

$-0.0264$

0.0143

0.1166

(0.0052)

(0.0039)

(0.0053)

$(0.0073)$

L Shortage $^{2}$

$\times$ Pos. Shortage

K Shortage ${ }^{2}$

K Shortage 2

$\times$ Pos. Shortage

L Shortage

$\times$ K Shortage

L Shortage

$\times$ K Sh. $\times$ Pos. Sh.

Post-reform

Pos. Shortage

$\times$ Post-reform

L Shortage ${ }^{2}$

$\times$ Post-reform

L Shortage $^{2}$

$\times$ Pos. Sh. $\times$ Post

K Shortage ${ }^{2}$

$\times$ Post-reform

K Shortage ${ }^{2}$

$\times$ Pos. Sh. $\times$ Post

L Shortage

$\times$ K Sh. $\times$ Post

L Sh. $\times$ K Sh.

$\times$ Pos. Sh. $\times$ Post

\begin{tabular}{|c|c|c|c|c|c|c|c|c|c|c|}
\hline & & & -0.0227 & -0.0022 & & & & & 0.0865 & 0.0491 \\
\hline & & & $(0.0035)$ & $(0.0054)$ & & & & & $(0.0028)$ & (0.0083) \\
\hline & & & 0.0248 & 0.0454 & & & & & 0.0351 & 0.1021 \\
\hline & & & $(0.0055)$ & $(0.0094)$ & & & & & $(0.0049)$ & $(0.0095)$ \\
\hline & & & 0.0007 & -0.0021 & & & & & -0.0689 & -0.1321 \\
\hline & & & $(0.0035)$ & $(0.0052)$ & & & & & $(0.0035)$ & $(0.0143)$ \\
\hline & & & -0.0373 & -0.0815 & & & & & 0.0797 & 0.1444 \\
\hline & & & $(0.0060)$ & $(0.0119)$ & & & & & $(0.0061)$ & $(0.0154)$ \\
\hline 0.0649 & & 0.0710 & & 0.0766 & & -0.1308 & & -0.1358 & & -0.1866 \\
\hline & & -0.1047 & & -0.0950 & & & & 0.2340 & & 0.2727 \\
\hline & & $(0.0116)$ & & $(0.0124)$ & & & & $(0.0151)$ & & (0.0157) \\
\hline & & 0.0003 & & 0.0419 & & & & 0.0664 & & 0.0843 \\
\hline & & $(0.0064)$ & & $(0.0074)$ & & & & $(0.0080)$ & & (0.0148) \\
\hline & & 0.0684 & & -0.0016 & & & & -0.1632 & & -0.0353 \\
\hline & & $(0.0082)$ & & $(0.0099)$ & & & & $(0.0103)$ & & (0.0173) \\
\hline & & & & -0.0326 & & & & & & 0.0493 \\
\hline & & & & $(0.0077)$ & & & & & & $(0.0084)$ \\
\hline & & & & -0.0150 & & & & & & -0.1490 \\
\hline & & & & -0.0265 & & & & & & 0.0630 \\
\hline & & & & $(0.0085)$ & & & & & & $(0.0146)$ \\
\hline & & & & 0.1008 & & & & & & -0.0929 \\
\hline & & & & $(0.0144)$ & & & & & & $(0.0181)$ \\
\hline 249.52 & 327.19 & 95.00 & 33.59 & 58.64 & & 874.67 & 1204.94 & 89.81 & 205.69 & 74.93 \\
\hline$[0.0001]$ & {$[0.0001]$} & {$[0.0001]$} & {$[0.0001]$} & {$[0.0001]$} & & {$[0.0001]$} & {$[0.0001]$} & {$[0.0001]$} & {$[0.0001]$} & [0.0001] \\
\hline 0.1831 & 0.1958 & 0.2006 & 0.1975 & 0.2034 & 0.2093 & 0.2202 & 0.2647 & 0.2689 & 0.2743 & 0.2812 \\
\hline 70,870 & 70,870 & 70,870 & 70,870 & 70,870 & 70,870 & 70,870 & 70,870 & 70,870 & 70,870 & 70,870 \\
\hline
\end{tabular}

F-test

Adjusted R2

70,870

0.2006
70,870

0.1975
70,870

(0.0063)

(0.0119)

(0.0064)

(0.0122)

0.1750

0.0357

0.2052

0.0154

$\begin{array}{llll}0.0109) & (0.0155) & (0.0110) & (0.0160)\end{array}$

$\begin{array}{llll}(0.0026) & (0.0079) & (0.0044) & (0.0142)\end{array}$

$\begin{array}{llll}0.0722 & 0.1502 & 0.0290 & 0.0908\end{array}$

$\begin{array}{llll}(0.0045) & (0.0089) & (0.0071) & (0.0155)\end{array}$

$0.0865 \quad 0.049$

$(0.0083)$

$(0.0049) \quad(0.0095)$

$-0.1321$

$0.0797 \quad 0.1444$

0.0121

0.0843

0.0148

0173)

0.0493

0.1490

$0.0107)$

0.0929

0181)

.0001]

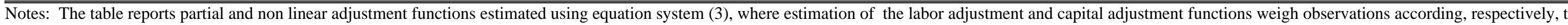

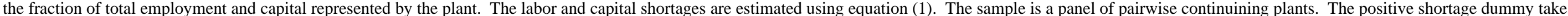

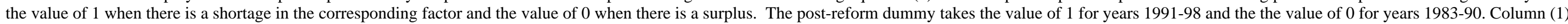

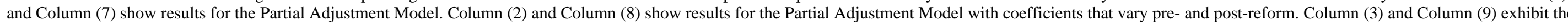

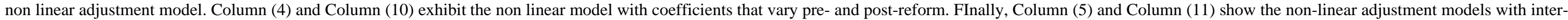
related capital and labor adjustments, while Column (6) and Column (12) extend that model to allow for asymmetries between the pre- and post-reform periods. 